\title{
The influence of EI Niño-Southern Oscillation regimes on eastern African vegetation and its future implications under the RCP8.5 warming scenario
}

\author{
Istem Fer ${ }^{1,2,3}$, Britta Tietjen ${ }^{4,5}$, Florian Jeltsch ${ }^{1,5}$, and Christian Wolff ${ }^{6,7}$ \\ ${ }^{1}$ Department of Plant Ecology and Nature Conservation, Institute of Biochemistry and Biology, University of Potsdam, \\ Am Mühlenberg 3, 14476 Potsdam, Germany \\ ${ }^{2}$ DFG Graduate School, Shaping the Earth's Surface in a Variable Environment, University of Potsdam, \\ Karl-Liebknecht-Str. 24, 14476 Potsdam, Germany \\ ${ }^{3}$ Department of Earth and Environment, Boston University, 685 Commonwealth Ave, MA 02215, USA \\ ${ }^{4}$ Biodiversity and Ecological Modelling, Institute of Biology, Freie Universität Berlin, Altensteinstr. 6, \\ 14195 Berlin, Germany \\ ${ }^{5}$ Berlin-Brandenburg Institute of Advanced Biodiversity Research (BBIB), 14195 Berlin, Germany \\ ${ }^{6}$ Climate Geochemistry Department, Max Planck Institute for Chemistry, Hahn-Meitner Weg 1, 55128 Mainz, Germany \\ ${ }^{7}$ International Pacific Research Center, School of Ocean and Earth Science and Technology, University of Hawai'i at Manoa, \\ Honolulu, HI 96822, USA
}

Correspondence to: Istem Fer (fer.istem@gmail.com)

Received: 15 February 2017 - Discussion started: 9 March 2017

Revised: 16 August 2017 - Accepted: 1 September 2017 - Published: 28 September 2017

\begin{abstract}
The El Niño-Southern Oscillation (ENSO) is the main driver of the interannual variability in eastern African rainfall, with a significant impact on vegetation and agriculture and dire consequences for food and social security. In this study, we identify and quantify the ENSO contribution to the eastern African rainfall variability to forecast future eastern African vegetation response to rainfall variability related to a predicted intensified ENSO. To differentiate the vegetation variability due to ENSO, we removed the ENSO signal from the climate data using empirical orthogonal teleconnection (EOT) analysis. Then, we simulated the ecosystem carbon and water fluxes under the historical climate without components related to ENSO teleconnections. We found ENSO-driven patterns in vegetation response and confirmed that EOT analysis can successfully produce coupled tropical Pacific sea surface temperature-eastern African rainfall teleconnection from observed datasets. We further simulated eastern African vegetation response under future climate change as it is projected by climate models and under
\end{abstract}

future climate change combined with a predicted increased ENSO intensity. Our EOT analysis highlights that climate simulations are still not good at capturing rainfall variability due to ENSO, and as we show here the future vegetation would be different from what is simulated under these climate model outputs lacking accurate ENSO contribution. We simulated considerable differences in eastern African vegetation growth under the influence of an intensified ENSO regime which will bring further environmental stress to a region with a reduced capacity to adapt effects of global climate change and food security.

\section{Introduction}

The 2010-2011 drought in the Horn of Africa, by some measures the worst drought in 60 years (Nicholson, 2014), is a reminder that rainfall in this politically and socioeconomically vulnerable region can fluctuate dramatically. El Niño- 
Southern Oscillation (ENSO) influence has long been at the centre of attention as a driver of these interannual fluctuations in eastern African rainfall (Indeje et al., 2000; Anyah and Semazzi, 2007; Nicholson, 2015); however, it is still an ongoing endeavour to qualify and quantify the future behaviour of ENSO regimes under the predicted future warming (Vecchi and Wittenberg, 2010; Miralles et al., 2014). In this study we aim to identify and quantify the ENSO contribution to the eastern African rainfall variability in order to increase our understanding of the future response of eastern African vegetation to rainfall variability related to changing ENSO regimes and climate, which can have dire consequences in this region in terms of food and social security.

\subsection{Eastern African climate}

Rainfall in eastern African climate is primarily controlled by the seasonal passage of the Intertropical Convergence Zone (ITCZ) (Nicholson, 2000), while mean annual precipitation varies from $<200$ to $>2000 \mathrm{~mm} \mathrm{yr}^{-1}$ (Nicholson, 2000) and dry season length can vary from 0 to $>8$ months. Interannual variations in the seasonal migration of the eastern African ITCZ are driven to a large extent by the ENSO (Ropelewski and Halpert, 1996) and its related impact through western Indian Ocean sea surface temperature (SST) anomalies (Goddard and Graham, 1999). The effect of ENSO on eastern African precipitation is diversified. Surface ocean warming in the western Indian Ocean (El Niño) leads to intensification and shifts of the ITCZ, bringing more precipitation to eastern Africa (Wolff et al., 2011), even though the direct teleconnection through the atmosphere tends to reduce rainfall (La Niña). These regions receive above average rainfall in El Niño years and below average rainfall in La Niña years during the OND months (Endris et al., 2013).

\subsection{Eastern African vegetation}

The control ENSO exerts on eastern African precipitation also manifests itself in the vegetation which is contingent upon the seasonal rainfall. Eastern Africa hosts a variety of biomes ranging from tropical rainforest to desert; however, the region is mainly dominated by arid or semi-arid vegetation (Bobe, 2006). The arid and semi-arid vegetation consists of species that can tolerate aridity for several months as a result of the exceedingly seasonal precipitation (Bobe, 2006). Agricultural activity also depends on this strong seasonality as it determines the cropping times (Shisanya et al., 2011). Maize, beans, coffee, tea, and wheat are among the important agricultural products of eastern Africa together with fruit products and grasses for livestock (FAOSTAT, 2016).

An adaptive management of the limited resources will shape the future severity of climate change impacts on food productivity in this rainfall-reliant set-up (Thornton et al., 2014). Therefore, a temporally and spatially extensive understanding of how the ecosystem dynamics in the region will respond to changing climate, and of particular concern to eastern Africa, to the ENSO regimes, is needed. Several studies related the variability in African vegetation to ENSO events (Shisanya et al., 2011; Ivory et al., 2013; Abdi et al., 2016; Detsch et al., 2016). However, the emergence of this relationship has been less of a focus, partly due to our imperfect knowledge of the nature of the future ENSO response to changing climate.

\subsection{ENSO impact on eastern African vegetation}

An opportunity to examine the ENSO-eastern African vegetation relationship is by means of using predictive tools such as vegetation models which have been successfully applied to determine and forecast regional vegetation dynamics (Moncrieff et al., 2014; Scheiter and Savadogo, 2016) as well as agricultural yields (Waha et al., 2013; Dietrich et al., 2014). In this study, we used the latest climate projections from the Intergovernmental Panel on Climate Change (IPCC) 5th assessment report for the Representative Concentration Pathway (RCP) 8.5 scenario, downscaled by the Coordinated Downscaling Experiment (CORDEX) (Nikulin et al., 2012; Endris et al., 2013) to drive such a process-based dynamic vegetation model, LPJ-GUESS (the Lund-PotsdamJena General Ecosystem Simulator). To be able to differentiate the vegetation variability due to ENSO, we removed the ENSO signal from the climate data and simulated the vegetation under the historical climate without components related to ENSO teleconnections. In the following sections, we look at the ENSO influence on eastern African vegetation (i) under present conditions, (ii) under projected future climate, and (iii) under a potentially increased ENSO intensity combined with future climate change. Finally, we discuss the effects of ENSO-related vegetation variability on the carbon and hydrological cycles, and its significance for mitigation efforts in the region.

\section{Methods}

\subsection{The LPJ-GUESS model}

We used the LPJ-GUESS dynamic vegetation model for our study. LPJ-GUESS is a mechanistic model in which ecosystem processes are simulated via explicit equations and is optimized for regional to global applications (Smith et al., 2001; Sitch et al., 2003; Gerten et al., 2004). Vegetation dynamics are simulated as the emergent outcome of growth, reproduction, mortality, and competition for resources among woody plant individuals and herbaceous vegetation.

The simulation units in this study are plant functional types (PFTs) distinguished by their growth form, phenology, photosynthetic pathway $\left(\mathrm{C}_{3}\right.$ or $\left.\mathrm{C}_{4}\right)$, bioclimatic limits for establishment and survival and, for woody PFTs, allometry and life history strategy. The simulations of this study were carried out in "cohort mode", in which, for woody 
PFTs, cohorts of individuals recruited in the same patch in a given year are represented by a single average individual, and are thus assumed to retain the same size and form as they grow. A sample instruction file used to run LPJ-GUESS in this study with all the parameters listed can be found under http://www.github.com/istfer/ENSOpaper/tree/master/ins.

Primary production and plant growth follow the approach of LPJ-DGVM (Sitch et al., 2003). Population dynamics (recruitment and mortality) are influenced by available resources and environmental conditions, and depend on demography and the life history characteristics of each PFT (Hickler et al., 2004). Disturbances such as wildfires are simulated based on temperature, fuel load, and moisture availability (Thonicke et al., 2001). Litter arising from phenological turnover, mortality, and disturbances enters the soil decomposition cycle. Decomposition rates depend on soil temperature and moisture (Sitch et al., 2003). Soil hydrology follows Gerten et al. (2004). A more detailed description of LPJ-GUESS is available in Smith et al. (2001). We used LPJ-GUESS version 2.1, which includes the PFT set and modifications described in Ahlström et al. (2012). LPJGUESS has already been successfully applied and validated to match present-day and mid-Holocene biome distributions of eastern Africa as suggested by data for both periods (Fer et al., 2016).

\subsection{Datasets tracking ENSO and regional vegetation}

To isolate the ENSO signal contribution to eastern African precipitation, we conducted an empirical orthogonal teleconnection (EOT) analysis between sea surface temperatures (SSTs) in the tropical Pacific Ocean and precipitation over eastern Africa (see section "Identifying the ENSO signal"). For historical extraction (1951-2005), we use the monthly National Oceanic and Atmospheric Administration Extended Reconstructed Sea Surface Temperature (NOAA ERSST) V4 dataset (Huang et al., 2014; Liu et al., 2014), available on $2^{\circ} \times 2^{\circ}$ global grids as a predictor field. As the response series, we used the monthly Climatic Research Unit Time Series (CRU TS) 3.20 dataset (Harris et al., 2014), available on $0.5^{\circ} \times 0.5^{\circ}$ global grids.

\subsubsection{LPJ-GUESS datasets}

LPJ-GUESS requires monthly climate (temperature, precipitation, cloud cover), atmospheric $\mathrm{CO}_{2}$ concentration, and soil texture as input data. For the historical period (1951-2005), we used monthly CRU TS 3.20 climate data. We chose these years for all historical analysis throughout the study as the historical simulations of CORDEX outputs are available for this period. For future projections (2006-2100), we used the outputs from the Coordinated Regional Climate Downscaling Experiment (CORDEX) programme for the African domain. To report the historical (1951-2005) and future (20062100) periods, we adhered to the CORDEX division of years for interpretability and reproducibility reasons. For the future scenario, we chose the baseline high-emission Representative Concentration Pathway (RCP) 8.5 scenario under the assumption that climate mitigation targets will not be met (Moss et al., 2010; Riahi et al., 2011). CORDEX, downscaled global climate models (GCMs) by using regional models, and the outputs are available from the ESGF-CoG data portal (https://esgf-node.llnl.gov/search/esgf-1ln1/). For the eastern African climate, we took the ensemble mean of nine models for future projections of the RCP8.5 scenario as these are the available, dynamically downscaled climate model outputs by the CORDEX project: CCCma CanESM2, CERFACS CNRM-CM5, QCCCE CSIRO Mk3-6-0, ICHEC ECEARTH, IPSL CM5A-MR, MIROC5, MPI ESM-LR, NCC NorESM1-M, and NOAA GFDL-ESM2M (full names of the models are given in the Appendix). Instead of working with individual models, we decided to drive our simulations with ensemble means as it has been shown to outperform individual models and show a better agreement with data (Endris et al., 2013). RCP8.5-compatible atmospheric $\mathrm{CO}_{2}$ values were also used as provided by the NOAA-GISS experiment (Nazarenko et al., 2015).

\subsubsection{Bias correction}

To eliminate biases originating from using the CRU climate dataset for present and model simulations for the future, we subtract the 1951-2005 climatology of the downscaled GCM ensemble from the 1951-2100 time series of the ensemble and add the anomalies on the CRU 1951-2005 climatology. This way we will be able to have a meaningful comparison between CRU-driven and GCM-driven vegetation model outputs while keeping the climate variability from the GCM simulations. We should note here that this would not change the ENSO signal we will retrieve from the GCM outputs (see next section) because we de-season and work with anomalies of the data field for our EOT analysis.

\subsubsection{Future Pacific SSTs}

For future Pacific SSTs, we used outputs from GCM simulations of the same models listed above for RCP8.5, except for ICHEC EC-EARTH, which was not available from the data portal at the time. However, these GCM outputs were not downscaled and standardized in terms of spatial resolution (they were all available in monthly time steps in terms of temporal resolution). We created raster files from these outputs and using the raster package ( $R, 2015)$, we resampled these rasters to bring them to the same spatial resolution as the NOAA ERSST V4 dataset, and we took the ensemble mean.

\subsection{Identifying the ENSO signal}

Here we first identify the ENSO signal as a driver for monthly eastern African precipitation variability over the his- 
torical period (1951-2005). To do this we investigate the teleconnectivity between the SSTs in the tropical Pacific Ocean and precipitation over eastern Africa by using EOTs. The method is explained by van den Dool et al. (2000) in detail, and Appelhans et al. (2015) implemented the original algorithm in the R "remote" package. Here, we only briefly present the major steps of the EOT analysis.

\subsubsection{EOTs}

In the EOT analysis, we aim to establish an explanatory relationship between the temporal dynamics of a (predictor) domain and the temporal variability of another (response) domain. Such predictor and response domains consist of gridded time series profiles: in this study the gridded monthly SST time series of the tropical Pacific as predictor and gridded precipitation time series of eastern Africa as the response. Then, the first step of EOT analysis is to regress these time series of each predictor domain grid $\left(N_{\mathrm{p}}\right)$ against the time series of each response domain grid $\left(N_{\mathrm{r}}\right)$ (Appelhans et al., 2015). This will result in a $\left(N_{\mathrm{p}} \times N_{\mathrm{r}}\right)$ number of regression fits after which we can calculate the sum of coefficients of determination per predictor grid (ending up with $N_{\mathrm{p}}$ sum of coefficients of determination values). Then, the grid with the highest sum will be identified as the "base point" of the leading mode as it explains the highest portion of the variance in the response domain (Appelhans et al., 2015). The time series at this base point is referred to as the leading teleconnection, or hereafter as the first EOT.

\subsubsection{Screening for ENSO signals}

We applied the EOT method to de-seasoned and de-noised data fields in order to retrieve a low-frequency signal such as ENSO: here we used the SSTs in the tropical Pacific Ocean as a predictor and precipitation over eastern Africa as a response. Then we proceeded to calculate the SST modes that most affect eastern African rainfall variability. We found the first EOT to be the ENSO signal. We compared this EOT with the Niño-3.4 Index to see whether we were able to isolate the ENSO signal. The commented code used for all methods is publicly available on Github (github.com/istfer/ ENSOpaper).

Before moving on to identifying future Pacific sea surface temperature-eastern African precipitation interactions, we applied the same extraction to historical GCM outputs (simulations) to see whether we can identify a similar relationship from GCM products. Finally, we prepared the model drivers with the modified ENSO signal we identified from the future simulations (see next section) and ran the model with these datasets (here we focused on precipitation data only, while precipitation varies in these simulations, and the others - temperature - were kept as they were in the climate datasets: present - CRU TS 3.2; future - CORDEX ensemble de-biased using CRU as explained above).

\subsection{Removing and intensifying the ENSO signal}

In order to investigate the contribution of the ENSO signal to eastern African precipitation, we removed the ENSO signal and explored the rainfall pattern with and without ENSO contribution as well as the resulting vegetation changes calculated by LPJ-GUESS. We used the "remote" package which specifically implements the EOT analysis and keeps track of calculated values in a structured workflow: the rainfall we are left with after removing the first EOT mode (which we identified as the ENSO signal) becomes the rainfall behaviour without ENSO contribution (within the "remote" package, this calculation of the residuals is automatically available after the calculation of the EOT modes). Therefore, if we take the difference between these residuals and the initial deseasoned and de-noised data, this will give us the amount that we need to subtract from the raw data field to obtain the rainfall behaviour without ENSO contribution. The steps are explained below as pseudocode:

i. De-season and de-noise the response and predictor fields.

$\mathrm{EA}_{\mathrm{r}, \mathrm{ds} \text {, dns }}$ : eastern African precipitation (response domain). Subscripts indicate raw, de-seasoned, and denoised respectively.

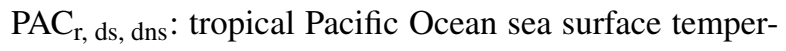
atures (SSTs) (predictor domain). Subscripts indicate raw, de-seasoned, and de-noised respectively.

$$
\begin{aligned}
& \mathrm{EA}_{\mathrm{ds}}=\text { de-season }\left(\mathrm{EA}_{\mathrm{r}}\right) \\
& \mathrm{PAC}_{\mathrm{ds}}=\mathrm{de}-\operatorname{season}\left(\mathrm{PAC}_{\mathrm{r}}\right) \\
& \mathrm{EA}_{\mathrm{dns}}=\mathrm{de}-\operatorname{noise}\left(\mathrm{EA}_{\mathrm{ds}}\right) \\
& \mathrm{PAC}_{\mathrm{dns}}=\text { de-noise }\left(\mathrm{PAC}_{\mathrm{ds}}\right)
\end{aligned}
$$

ii. Conduct EOT analysis:

$$
\mathrm{EOT}_{\text {modes }} \longleftarrow \mathrm{EOT}\left(\mathrm{EA}_{\mathrm{dns}} \sim \mathrm{PAC}_{\mathrm{dns}}\right)
$$

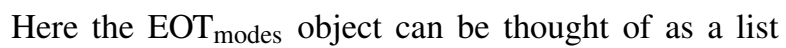
that stores both the time series of the modes and the reduced fields obtained after the removal of each mode, slope, and intercept of the fields - for more details, see Appelhans et al. (2015).

iii. Calculate the difference (Diff) between the de-seasoned, de-noised data $\left(\mathrm{EA}_{\mathrm{dns}}\right)$ and the rainfall behaviour without ENSO contribution from the information that is already stored in the resulting $\mathrm{EOT}_{\text {modes }}$ object (the ENSO signal is the first mode; therefore, the rainfall behaviour we are left without ENSO will be the EA $_{\text {modes, }}$ rr1 where subscript rr1 indicates the "response residual" after the removal of the first EOT mode:

Diff $=\mathrm{EA}_{\mathrm{dns}}-\mathrm{EA}_{\text {modes, }}$,r1. 


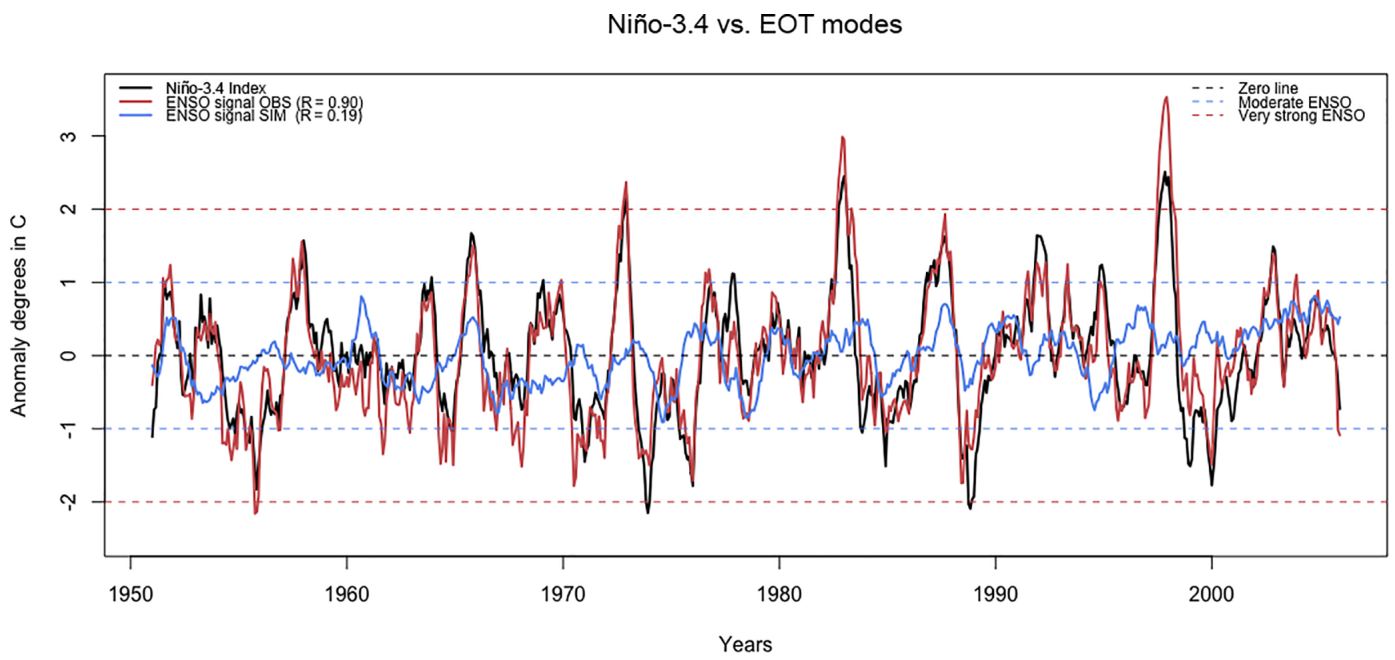

Figure 1. The comparison between the Niño-3.4 Index recorded by NOAA (black line), time series of the first mode obtained from the EOT analysis of observed CRU-NOAA datasets (red), and time series of the first mode obtained from the EOT analysis of ensembles of the climate model simulations (blue). Black dashed line: zero line. Blue dashed lines $\pm 1.0^{\circ}$ anomaly thresholds for categorizing moderate ENSO events. Red dashed lines: $\pm 2.0^{\circ}$ anomaly thresholds for categorizing very strong ENSO events.

iv. If we subtract this difference from the initial raw response field $\left(\mathrm{EA}_{\mathrm{r}}\right)$, we will obtain the eastern African precipitation without ENSO contribution $\left(\mathrm{EA}_{\mathrm{r}, \text { woENSO}):}\right.$

$\mathrm{EA}_{\mathrm{r}, \mathrm{woENSO}}=\mathrm{EA}_{\mathrm{r}}-$ Diff.

v. As EOT analysis is basically a regression analysis, we can also obtain the ENSO contribution (Diff) from the regression equation as shown below (which will become handy when we insert back the intensified ENSO signal):

Diff $=\mathrm{EOT}_{\text {modes, eot1 }} \times \mathrm{EOT}_{\text {modes, ri1 }}-\mathrm{EOT}_{\text {modes, } \mathrm{rs} 1}$.

Here $\mathrm{EOT}_{\text {modes, eot } 1}, \mathrm{EOT}_{\text {modes, ri1 }}$, and $\mathrm{EOT}_{\text {modes, rs1 } 1}$ refer to the EOT time series of the first mode (the ENSO signal); the intercept of and slope of the response field are calculated for the first mode (Appelhans et al., 2015).

vi. Then, it is possible to modify the future ENSO signal (EOT modes, eotF) obtained from EOT analysis of simulation datasets, re-calculate its contribution to the eastern African rainfall (Diff new $_{\text {, }}$, and add this amount back on the precipitation data without an ENSO signal $\left(\mathrm{EA}_{\mathrm{r}, \text { woENSO }}\right)$ to obtain new precipitation amounts $\left(\mathrm{EA}_{\mathrm{r}, \mathrm{new}}\right)$ due to a new signal. We can later use this $\mathrm{EA}_{\mathrm{r} \text {, new }}$ as the future precipitation input to our vegetation model to drive future simulations.

Diff $_{\text {new }}=$ EOT $_{\text {modes, eotF }} \times$ EOT $_{\text {modes, ri1 }}-$ EOT $_{\text {modes, }}$ rs1
$\mathrm{EA}_{\mathrm{r}, \text { new }}=\mathrm{EA}_{\mathrm{r}, \text { woENSO }}+$ Diff $_{\text {new }}$

Here it is noticeable that slope(s) and intercept(s) would also have been different if the ENSO signal was changed (EOT modes, eotF). However, this simplification is adequate for the experiments in this paper. Moreover, we used the intercept and slope we retrieved from the EOT analysis on observational datasets while recalculating the new difference (Diff new $_{\text {) }}$ ) due to an intensified ENSO signal, because the eastern African rainfall patterns explained by tropical Pacific SSTs in the GCM simulations are different from observations (Figs. A1 and $\mathrm{A} 2$ in the Appendix). By using slopes and intercepts obtained from the observational data, we were also able to preserve the more accurate patterns in rainfall differences.

vii. Finally, we obtained the modified ENSO signal $\left(\mathrm{EOT}_{\text {modes, eotF}}\right)$ in Eq. (7) by detrending (fitting a locally weighted scatterplot smoother (LOWESS) smoother and removing it from the signal) and multiplying the ENSO signal we extracted from the future simulations (de-seasoned and de-noised GCM simulations for eastern African rainfall, $\mathrm{EA}_{\mathrm{dns}}$, ftr, and tropical $\mathrm{Pa}$ cific SSTs, $\mathrm{PAC}_{\mathrm{dns}}$, ftr $)$ by a coefficient $(k=3)$ such that the peaks of the new signal would be as strong as the observed anomalies $\left( \pm 2.5^{\circ} \mathrm{C}\right.$, Figs. 1 and $\left.\mathrm{A} 3\right)$. For the code of this step, see the IdentifyModifyFutureENSO.R script at github.com/istfer/ENSOpaper.

$$
\begin{aligned}
& \mathrm{EOT}_{\text {modes, ftr }} \longleftarrow \mathrm{EOT}\left(\mathrm{EA}_{\mathrm{dns}, \mathrm{ftr}} \sim \mathrm{PAC}_{\mathrm{dns}, \mathrm{ftr}}\right) \\
& \text { EOT }_{\text {modes, eotF }}=k \times \operatorname{detrend}\left(\mathrm{EOT}_{\text {modes, ftr, eot } 1}\right)
\end{aligned}
$$



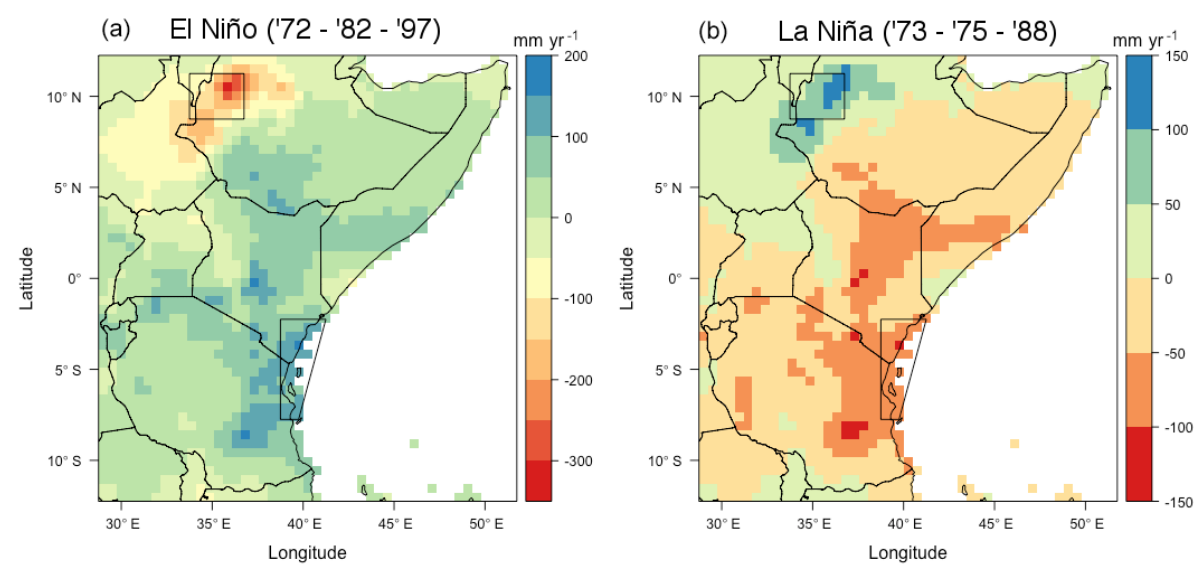

Figure 2. Regional maps of anomalies $\left(\mathrm{mm} \mathrm{yr}^{-1}\right)$ for the strongest three $(1972,1982,1997)$ El Niño (a) and $(1973,1975,1988)$ La Niña (b) events in the 1951-2005 period (anomalies were calculated by subtracting precipitation without ENSO contribution from precipitation with ENSO contribution). Northern inner and southern coastal transects chosen for reporting results on vegetation simulations.

\section{Results}

\subsection{EOT analysis - extracting the ENSO signal}

We compared the first EOT mode extracted after deseasoning and de-noising the fields as explained by Appelhans et al. (2015) to the Niño-3.4 Index recorded (Fig. 1). The high correlation between the two $(R=0.90)$ confirms that we were able to extract the ENSO signal by conducting the EOT analysis. In the predictor domain (tropical Pacific SSTs), the Niño-3.4 region was found to be the area which explains the most variance in the response domain (eastern African precipitation), as expected (Fig. A1). The time series of the first EOT explains $0.85 \%$ of the rainfall variability over the analysed period here (1951-2005). This small amount is not surprising, because eastern African precipitation follows a strong seasonal pattern following the position of the Intertropical Convergence Zone (ITCZ) within the year. Therefore, seasonality alone explains most of the variability in eastern African rainfall. In addition, due to the complex topographical setting of the region, local conditions play a major role in the variation of the rainfall. Still, when we de-season and de-noise the raw data fields to identify lowfrequency signals such as ENSO, the ENSO signal emerged as the most important teleconnection between tropical Pacific SST anomalies and eastern African precipitation.

Having successfully extracted the ENSO signal from the observation datasets, we applied the same procedure with the outputs of the climate models. We used an ensemble of SSTs from eight GCM outputs as the predictor field and an ensemble of rainfall from nine GCMs downscaled by CORDEX as the response domain. The comparison between the calculated first EOT time series to the Niño-3.4 Index observed was much poorer $(R=0.19)$ (Fig. 1), which indicates that GCMs are not capturing the coupled Pacific SST-eastern African rainfall teleconnection. Another striking feature that can be observed in Fig. 1 is the smoothness of the time series of the first mode calculated from the EOT analysis on ensembles of climate model outputs when compared to the recorded index and the calculated ENSO signal from the observation datasets. In other words, the ENSO signal retrieved from the EOT analysis on the climate model outputs is nowhere near as strong as the others. According to this signal obtained from the simulation datasets, the only ENSO events that happened during the 1951-2005 period were in the "weak" category (Fig. 1). Finally, the calculated patterns were different than the EOT analysis of observed datasets (the corresponding figure is given in Fig. A2): the areas where the sum of the coefficients of determination were the highest were again situated around the Niño-3.4 region but closer to the Niño-4 region this time (Fig. A2, left panel). Spatially, the north-eastern and central parts of the response domain are the most explained, whereas previously it was more centralized around the coastal equatorial parts of the region (Fig. A2, right panel).

\subsection{Historical simulations with and without the ENSO signal}

After calculating the ENSO signal, we removed the amount due to ENSO from the eastern African precipitation (CRU precipitation), and simulated eastern African vegetation using both datasets $\left(\mathrm{CRU}_{\text {normal }}\right.$ and $\left.\mathrm{CRU} \mathrm{U}_{\text {withoutENSO}}\right)$, to see its effect on vegetation. As can clearly be seen from Fig. 1, the impact of the ENSO signal is not the same everywhere in the eastern African domain, which means removing the ENSO signal would have different effects on the rainfall amount. Regional maps of rainfall anomalies for the three strongest El Niño (1972, 1982, 1999) and La Niña (1973, 1975, 1988) events in the 1951-2005 period are given in Fig. 2. Here we show what the rainfall would be if there were no influence by the Pacific SSTs, particularly during these 3 years. Especially 
Table 1. Paired $t$ test results to test whether there is a significant difference in the vegetation simulations that are driven with and without ENSO contributions for the three strongest ENSO events during the historical period (1951-2005) and with and without intensified ENSO signal for the strongest ENSO events during the future period (2006-2100). Italics indicate insignificant differences according to the $p=0.05$ threshold. Significant $p$ values indicate rejection of the $H_{0}$ in favour of the alternative; that is, the true difference in means is not equal to 0 .

\begin{tabular}{|c|c|c|c|c|c|c|c|}
\hline & & \multicolumn{2}{|c|}{$\begin{array}{l}\mathrm{NPP} \\
\left(\mathrm{kgCm}^{-2} \mathrm{yr}^{-1}\right)\end{array}$} & \multicolumn{2}{|c|}{$\begin{array}{l}\text { NEE } \\
\left(\mathrm{kgCm}^{-2} \mathrm{yr}^{-1}\right)\end{array}$} & \multicolumn{2}{|l|}{$\begin{array}{l}\text { RUNOFF } \\
\left(\mathrm{mm} \mathrm{yr}^{-1}\right)\end{array}$} \\
\hline & & El Niño & La Niña & El Niño & La Niña & El Niño & La Niña \\
\hline \multirow[t]{2}{*}{ Historical } & $\mathrm{N}$ & $\begin{array}{l}p<0.05 \\
\text { md: }-0.056\end{array}$ & $\begin{array}{l}p<0.05 \\
\text { md: } 0.035\end{array}$ & $p=0.089$ & $p=0.1$ & $\begin{array}{l}p<0.05 \\
\text { md: }-41.35\end{array}$ & $\begin{array}{l}p<0.05 \\
\text { md: } 22.21\end{array}$ \\
\hline & S & $\begin{array}{l}p<0.05 \\
\text { md: } 0.084\end{array}$ & $\begin{array}{l}p<0.05 \\
\text { md: }-0.074\end{array}$ & $\begin{array}{l}p<0.05 \\
\text { md: }-0.088\end{array}$ & $\begin{array}{l}p<0.05 \\
\text { md: } 0.087\end{array}$ & $\begin{array}{l}p<0.05 \\
\text { md: } 19.41\end{array}$ & $\begin{array}{l}p<0.05 \\
\text { md: }-10.74\end{array}$ \\
\hline \multirow[t]{2}{*}{ Future } & $\mathrm{N}$ & $\begin{array}{l}p<0.05 \\
\text { md: }-0.052\end{array}$ & $\begin{array}{l}p<0.05 \\
\text { md: } 0.033\end{array}$ & $p=0.93$ & $p=0.58$ & $\begin{array}{l}p<0.05 \\
\text { md: }-10.91\end{array}$ & $\begin{array}{l}p<0.05 \\
\text { md: } 46.97\end{array}$ \\
\hline & $\mathrm{S}$ & $\begin{array}{l}p<0.05 \\
\text { md: } 0.049\end{array}$ & $\begin{array}{l}p<0.05 \\
\text { md: }-0.101\end{array}$ & $\begin{array}{l}p<0.05 \\
\text { md: }-0.113\end{array}$ & $\begin{array}{l}p<0.05 \\
\text { md: } 0.173\end{array}$ & $\begin{array}{l}p<0.05 \\
\text { md: } 5.66\end{array}$ & $p=0.06$ \\
\hline
\end{tabular}

The locations of the northern $(\mathrm{N})$ and southern $(\mathrm{S})$ sites are shown in Fig. 2. $p$ : $p$ value; md: mean of the differences. NPP: net primary productivity; NEE: net ecosystem exchange; RUNOFF: surface runoff.

coastal Kenya and Tanzania experience a strong change in the amount of rainfall they receive: during the El Niño periods, these parts of eastern Africa receive up to $200 \mathrm{~mm} \mathrm{yr}^{-1}$, more rain than they would receive otherwise, while they receive $\approx 100 \mathrm{~mm} \mathrm{yr}^{-1}$ less rain during the La Niña years. The impact is the opposite for the western part of Ethiopia, receiving $\approx 200 \mathrm{~mm} \mathrm{yr}^{-1}$ less rainfall during El Niño years, and $\approx 100 \mathrm{~mm} \mathrm{yr}^{-1}$ more during La Niña years. To provide a closer look at the impacts of ENSO-related variability on vegetation, we report the results on vegetation simulations within the two transects, where we see the strongest impacts over these two oppositely behaving, coastal and northwestern, regions (Fig. 2).

We drove the dynamic vegetation model once with the CRU dataset as is and once with the CRU dataset with removed ENSO contribution. Results are reported for the previously mentioned northern and southern sites in Fig. 3 and Table 1. Outputs from the northern-inner part show more variability within the chosen grid cells for this region. Indeed, this region is on the western edge of the Ethiopian Plateau, with a transition of biomes from mountainous forests to woodlands and savannas (Fer et al., 2016). As the rainfall patterns in relation to the ENSO signal were the opposite between these regions (Fig. 2), we expect to see that the response of these regions to the removal of the ENSO signal is the opposite, and this is indeed what we see in Fig. 3: while outputs such as net primary productivity (NPP), net ecosystem exchange (NEE), and surface runoff (RUNOFF) for the northern site were less than otherwise they would be for El Niño events, they would be higher La Niña events. And the opposite behaviour is true for the southern site.

In order to test the difference between the vegetation simulated under climate with ENSO contribution and the vegeta-

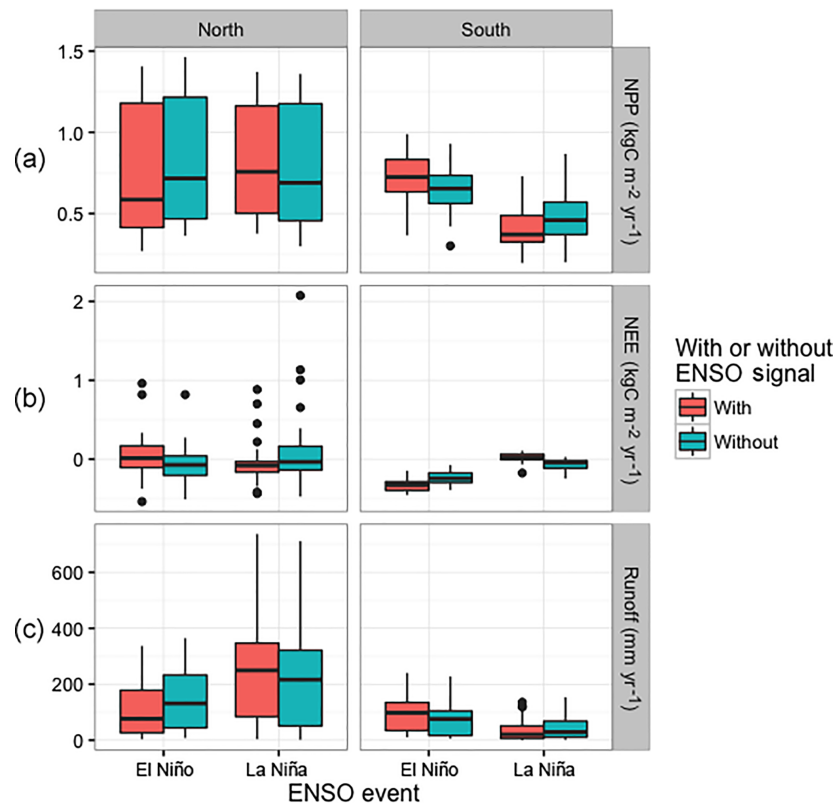

Figure 3. Carbon and water fluxes from the northern and southern transects, simulated under climate with and without ENSO contribution, for the strongest three $(1972,1982,1997)$ El Niño and (1973, 1975, 1988) La Niña events in the 1951-2005 period. (a) Net primary productivity (NPP). (b) Net ecosystem exchange (NEE). (c) Total runoff. Locations of the northern-inner and southern-coastal sites are given in Fig. 2.

tion simulated under climate with removed ENSO contribution, we conducted a paired $t$ test on the outputs. The results (Table 1) show that except for NEE for northern sites, all differences between the vegetation simulated with and without ENSO impact were significant. In summary, ENSO contribu- 
tion is significantly affecting the eastern African vegetation, and we would expect different vegetation if there were no ENSO events.

\subsection{Future simulations with and without the intensified ENSO signal}

We conducted the same paired $t$ test for the northern and southern sites for the future simulations (Table 1). In the northern site where an intensified signal leads to less (more) NPP during El Niño (La Niña) years, the mean difference is $-52(+32.6) \mathrm{g} \mathrm{C} \mathrm{m}^{-2} \mathrm{yr}^{-1}$ between the vegetation simulated under future climate with and without an intensified ENSO signal. In the southern site where an intensified signal leads to more (less) NPP during El Niño (La Niña) years, the mean difference is $+49.1(-101.1) \mathrm{g} \mathrm{C} \mathrm{m}^{-2} \mathrm{yr}^{-1}$ between the vegetation simulated under future climate with and without an intensified ENSO signal. While the mean differences for NEE were not significant at the northern site, the southern site stores 112.7 (173.1) $\mathrm{g} \mathrm{C} \mathrm{m}^{-2} \mathrm{yr}^{-1}$ more (less) carbon under the intensified ENSO scenario during the El Niño (La Niña) years.

Another noteworthy output is that the northern site has a lot more runoff during the La Niña years under the intensified ENSO scenario. This is especially clear in Fig. 4 where spatial patterns of the differences in the simulated future vegetation under the RCP8.5 scenario with and without intensified ENSO are shown. The opposite behaviour of the northern parts of eastern Africa under El Niño vs. La Niña conditions can also be observed in NPP and RUNOFF figures, whereas for NEE differences a particular pattern is not emergent. This is mainly because NEE values can themselves be negative (flux to ecosystem) and positive (release to atmosphere).

The opposite temporal behaviours of the northern and southern transects are also clear in Fig. 5, which shows the time series of the differences between simulated NPP, NEE, and RUNOFF under climate drivers with and without an intensified ENSO signal. In line with the characterized behaviours above, we simulated higher (lower) NPP for the southern transect (red line) for the El Niño (La Niña) years under the intensified scenario, whereas the opposite is true for the northern transect (black line). The higher amplitude of the RUNOFF difference for the northern transect is notable in the bottom panel (Fig. 5).

\section{Discussion}

\subsection{Identifying and intensifying the ENSO signal}

Eastern African rainfall variability and especially the contribution of the ENSO has been investigated before (Indeje et al., 2000; Schreck and Semazzi, 2004). Here we used a different method, EOT analysis, to quantitatively calculate the ENSO contribution, and found the spatial correla- tion patterns over the eastern Africa region to be in agreement with previous studies which independently looked at Pacific SST drivers for eastern African precipitation (Anyah and Semazzi, 2007). The ENSO signal identified through this method also shows strong correlation with the NOAA Niño-3.4 Index, which means the EOT method was a suitable choice for our analysis.

Using the EOT method, we presented a relatively conservative estimate of ENSO variability in eastern African rainfall, because we considered the direct tropical Pacific teleconnection only. However, there are accompanying changes: ENSO events are linked to the Indian Ocean Dipole (IOD), which more directly influences EA rainfall (Black et al., 2003). It has been suggested that, subsequent to ENSO triggering, internal Indian Ocean dynamics could take over. More specifically, eastern African rainfall increases as the western Indian Ocean gets warmer, which is often associated with ENSO forcing. However, the warmer western Indian Ocean can weaken the rains when it interacts with south-easterly atmospheric circulations (Schreck and Semazzi, 2004). The exact relationship and discrepancies between IOD and ENSO behaviours are yet to be revealed (Lim et al., 2017). Still, we found the ENSO-eastern Africa connection to be as robust as previous studies (Indeje et al., 2000; Anyah and Semazzi, 2007) and did not delve into the IOD relationship. Also, we were motivated by the previous studies that have identified ENSO influence as being important in dryland vegetation dynamics (Ahlström et al., 2015; Abdi et al., 2016). Hence, we focused on reporting more comparable results with those. Another factor that could affect our estimations is atmospheric latency. In our analysis, we did not consider any time lags for the tropical Pacific SST anomalies and eastern African precipitation teleconnection, but a time lag can be expected due to atmospheric circulation processes, and the influence of SST anomalies might not develop instantaneously. Therefore, if we account for this time lag, we might explain even more of the rainfall variance. For a more comprehensive study of SST influences on eastern African rainfall, see Appelhans and Nauss (2016).

The EOT method, which is shown here to be effective on the historical observations, produced different eastern African rainfall variability patterns due to Pacific SSTs when GCM outputs were used. Also, the ENSO signal retrieved was much weaker than the one extracted from the observation datasets in terms of both ENSO event strength and the match (correlation) with the Niño-3.4 Index. As a preliminary investigation (not shown), we conducted the EOT analysis across a mixture of observed-simulated datasets:

$$
\begin{aligned}
& \text { Pacific SSTs } \text { observed }(\text { NOAA ERSST) } \\
& \text { - eastern African precipitation } \\
& \text { simulated }_{\text {(CORDEX), }}
\end{aligned}
$$

and 

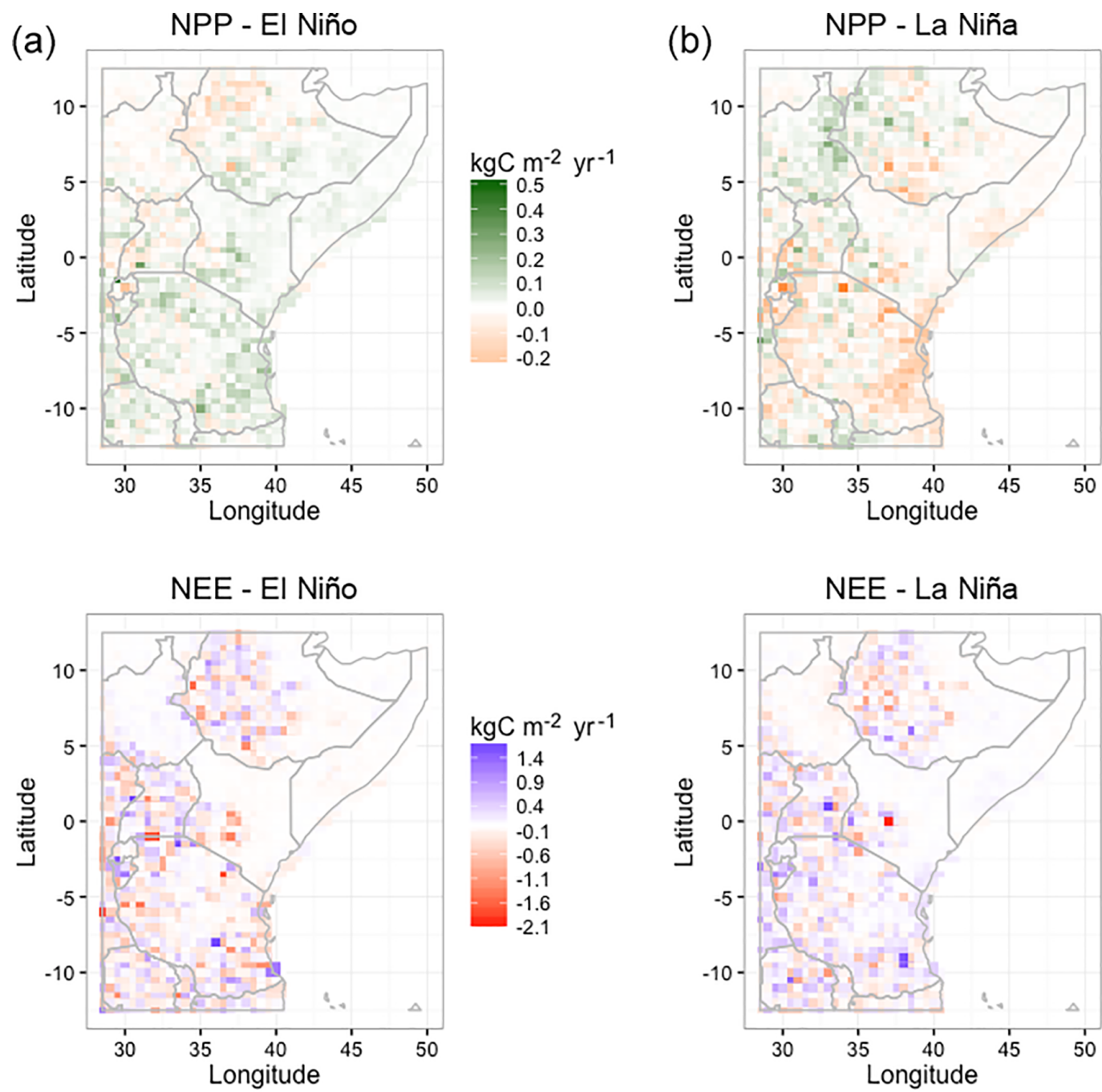

$$
\mathrm{kgC} \mathrm{m} \mathrm{m}^{-2} \mathrm{yr}^{-1}
$$

$-0.2$

0.1

0.0

$-0.1$

$-0.2$

-0.2
-0.3

$-0.4$

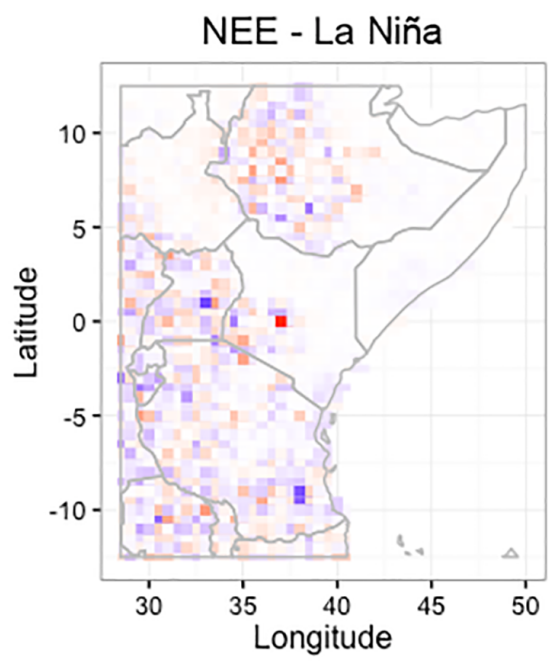

$\mathrm{kgC} \mathrm{m} \mathrm{m}^{-2} \mathrm{yr}^{-1}$
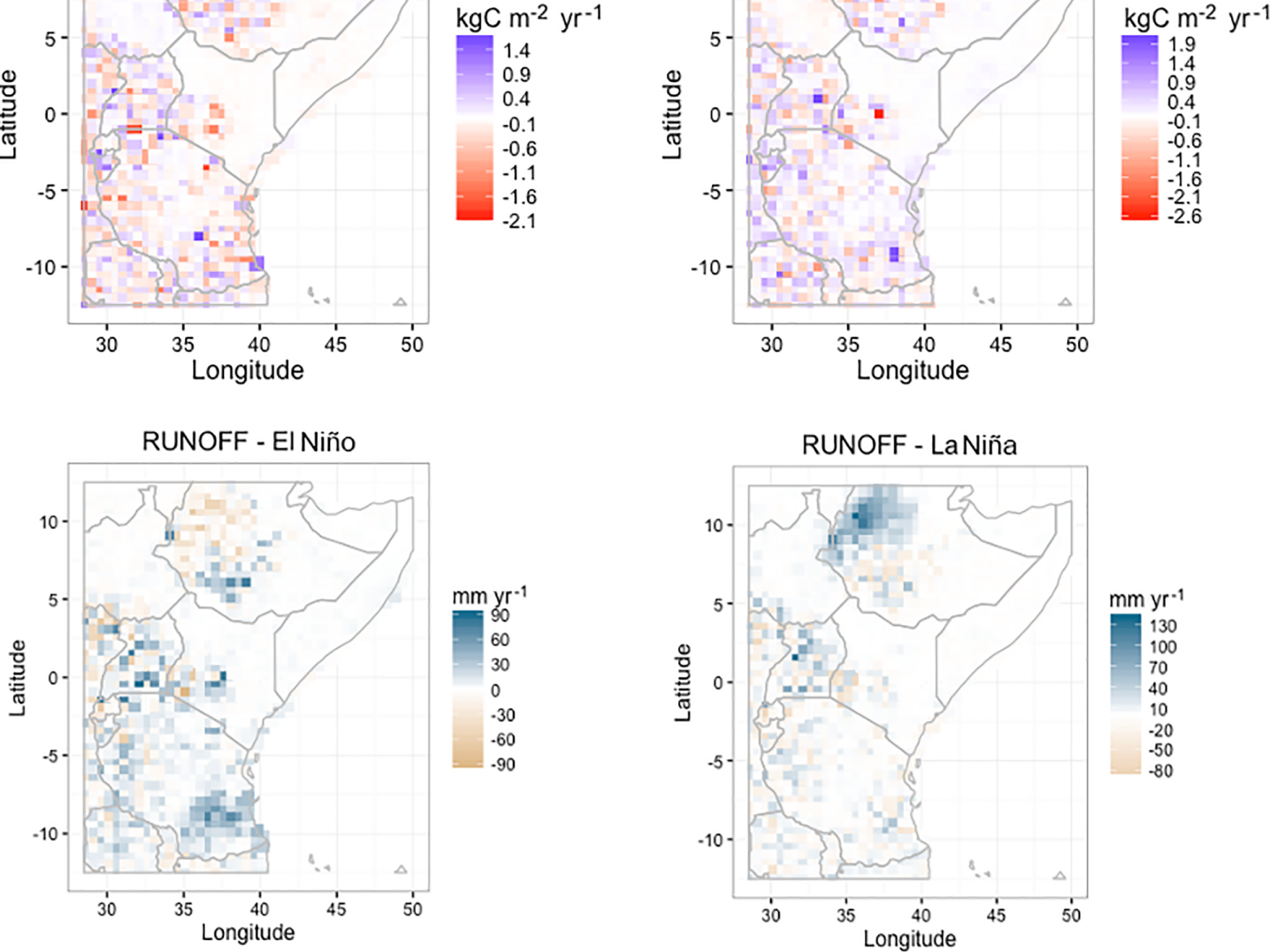

Figure 4. Simulated future differences in the NPP, NEE, and RUNOFF between, with, and without intensified ENSO runs. (a) Mean differences for the strong El Niño years $\left(\geq+1.5^{\circ} \mathrm{C}\right)(2025,2026,2077)$ were calculated by subtracting the GCM-ensemble-driven simulations without modification from the GCM-ensemble-driven future simulations with an intensified ENSO signal. (b) Same for strong future La Niña events $\left(\leq-1.5^{\circ} \mathrm{C}\right)(2039,2049,2084)$. 

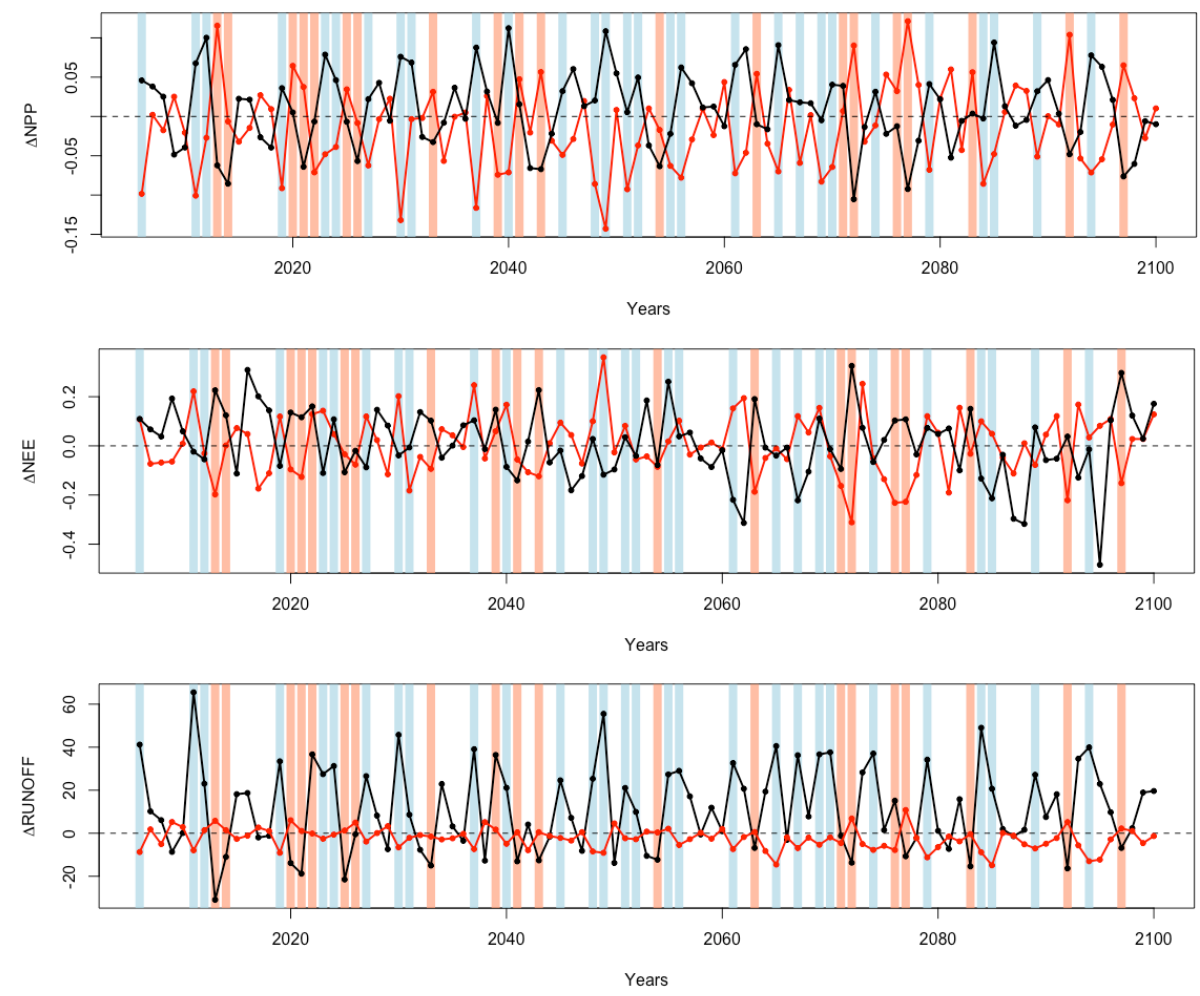

Figure 5. Temporal differences in the NPP, NEE, and RUNOFF according to future simulations with and without intensified ENSO contribution ( $\Delta=$ with intensification - without intensification). Black line: northern transect; red line: southern transect. Vertical blue lines: all moderate $\left(<-1.0^{\circ} \mathrm{C}\right)$ La Niña years identified for the future period (2006-2100); vertical pink lines: moderate $\left(>1.0^{\circ} \mathrm{C}\right)$ El Niño years. The units are the same as Fig. 4.

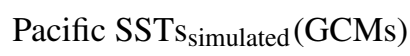

- eastern African precipitation observed $(\mathrm{CRU})$.

The ENSO signal retrieved from the Pacific SSTs $\mathrm{s}_{\text {observed }}-$ eastern African precipitation simulated $_{\text {pair was a better match }}$ to the Niño-3.4 Index than the one extracted from the simulated-simulated pair, but still worse than the one extracted from the observed-observed dataset pair, whereas the ENSO signal retrieved from the Pacific SSTs $s_{\text {simulated }}-$

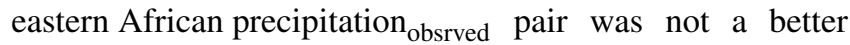
match to the Niño-3.4 Index than the one extracted from the simulated-simulated pair. This quick test indicated that the GCM-simulated tropical Pacific SSTs are the main source of the poor teleconnection identified from the simulatedsimulated pair and that a dynamic downscaling of the tropical Pacific SSTs might improve the ocean-atmosphere coupled teleconnection. However, more formal tests are needed to draw conclusions on this matter, which was beyond the scope of this study.

\subsection{Present-day simulations}

Despite the fact that our estimation of ENSO contribution to the eastern African interannual rainfall variability was conservative, the precipitation difference between, with, and without ENSO contribution was equivalent to 1 or even 2 rainy months for some of the grid cells. These regions already receive a small amount of rainfall and even minor differences are critical for agricultural food production and the productivity of the natural ecosystem that sustains a large biodiversity. We found an up to $0.1 \mathrm{kgC} \mathrm{m}^{-2} \mathrm{yr}^{-1}$ mean difference in NPP in the southern parts of the region solely due to ENSO contribution.

We found that ENSO influence on net ecosystem exchange is also prominent in the semi-arid ecosystems of eastern Africa. Especially in the southern-coastal parts, the ecosystem releases more into the atmosphere during La Niña events, whereas it would store more carbon otherwise. This would also have implications for the global carbon cycle, as it has previously been found that regional responses of semiarid ecosystems, mainly occupying low latitudes, play an important role in determining the trend in $\mathrm{CO}_{2}$ uptake by terrestrial ecosystems (Ahlström et al., 2015). For instance, La Niña events are associated with large carbon sinks in Australian semi-arid ecosystems due to increased precipitation, and the 2011 anomaly in the global carbon sink was mainly attributed to the response of Australian ecosystems (Poulter et al., 2014). While semi-arid ecosystems of eastern Africa 
might play a smaller role than Australian ones (simply due to the difference in the area they cover), it would still influence the magnitude and trend of the global carbon sink by terrestrial ecosystems. Furthermore, Forzieri et al. (2017) report the importance of the interplay between vegetation cover (in terms of leaf area index, LAI) and surface biophysics, finding an amplification of their relationship under extreme warm-dry and cold-wet years. Here we found that the ENSO contribution impacts the temporal LAI variability in eastern Africa considerably (Fig. A5), presenting a good example of such temporal variations that can play significant roles in modulating key vegetation-climate interactions. According to the analysis by Forzieri et al. (2017), the magnitudes of differences we found in our study due to accounting for an intensified ENSO signal are influential on the surface energy balance components such as longwave outgoing radiation, latent heat flux, and sensible heat flux. Our findings reiterate the importance of considering ENSO contribution in carbon and energy budget calculations for any region that is influenced by ENSO variability.

Here we also report ENSO influence on surface runoff as excess runoff response causes problems in eastern Africa. In this region, Rift Valley fever (RVF) and malaria outbreaks are threatening the livelihood of the society and these vectorborne diseases are transmitted by mosquitoes who breed in flooded low-lying habitats (Meegan and Bailey, 1989; Kovats et al., 2003; Kelley-Hope and Thomson, 2008). For example, a major RVF outbreak during late 1997 to early 1998 has been linked to the heavy and prolonged rains that are associated with the 1997-1998 El Niño event (Trenberth, 1998), in agreement with our results where we found that the southern coastal site experiences higher runoff during El Niño events than otherwise it would do.

Another important ecological factor to be considered for eastern African vegetation dynamics is fire. The fire occurrence in LPJ-GUESS depends on the atmospheric temperature values, and moisture and litter availability. Therefore, although we did not calibrate LPJ-GUESS fire parameters for eastern Africa or explicitly change fire regimes under any of the scenarios, the model simulated the changes in fire behaviour due to different environmental states implicitly. More specifically, for the southern coastal part, a higher mean expected return time of fire was simulated during the El Niño years for simulations with ENSO contribution than without due to higher moisture availability during ENSO years for this region (not shown). For the same site, the opposite was true for La Niña years, and the whole behaviour was reversed for the northern site. A more sophisticated fireENSO-vegetation interplay can be further investigated using models that have an individual level representation of fire response, such as aDGVM2 (Scheiter et al., 2013).

In this study, we did not further calibrate the LPJ-GUESS PFT parameters, as they have been calibrated and validated for the region by previous studies (Doherty et al., 2010; Fer et al., 2016). It is possible that these point estimate values do not capture the uncertainties associated with the PFT parameters. However, previous studies have shown LPJ-GUESS parameters to be robust (Zaehle et al., 2005; Doherty et al., 2010). In addition, as we used the same set of parameters for all runs, the discrepancies simulated with and without ENSO contribution would still hold. As LPJ-GUESS spins up from bare ground, we also do not expect much uncertainty influencing the model predictions with and without ENSO contribution due to initial conditions. On the other hand, we expect the driver uncertainty to dominate the uncertainty around model predictions. However, that is exactly what we aimed at quantifying in this study, as is discussed in the following sections.

\subsection{Scenario selection and future simulations}

In the results for the future simulations, the total surface runoff and NPP responses were considerably underestimated. Under the intensified ENSO scenario, an excessive amount of runoff is simulated for the northern parts during La Niña years and for the southern parts during El Niño years, which would exacerbate the disease events in the region. Likewise, the simulated low amounts of runoff for the northern parts during El Niño years indicate drought events in this part of the region. This effect can also be seen in the simulated NPP responses, which decrease considerably for the northern parts during El Niño years. Furthermore, the amounts we calculated here agree well with previous studies showing changes in NPP supply associated with ENSO events in sub-Saharan African drylands (Abdi et al., 2016).

The regions identified to be impacted by ENSO the most are also the regions that are currently undergoing the highest woody vegetation decrease and human population increase in eastern Africa according to the analysis by Brandt et al. (2017). In our future simulations, we simulated an increase in woody vegetation LAI due to climate change (Fig. A4) in those regions of eastern Africa. It requires further analysis to say whether this anthropogenic reduction in woody vegetation could be met by future climate and atmospheric $\mathrm{CO}_{2}$-related increase. However, it reinforces the essentiality of accounting for ENSO influence, as independent analyses show increasing stress over this region.

In this study, we chose RCP8.5 as our future warming scenario for two reasons: (i) we aimed to follow the current trajectory, which points beyond the RCP8.5 scenario given the observed trends (Sanford et al., 2014), and (ii) we intended to capture the furthest range presented by RCPs, as that is the extent to be considered for the assessment of ecosystem responses and mitigation efforts. However, we found the ENSO signal as identified by the EOT method to be very weak in the GCM outputs, and for the future simulations we intensified the ENSO signal such that very strong ENSO years can also be experienced as in the real-world case. It could be argued that we did not even apply an extra intensification due to RCP8.5, and this discrepancy would hold 
regardless of the future scenario. Considering that we are expected to experience even stronger ENSO events in the future than today (Cai et al., 2014, 2015), we could have intensified this signal even more. However, our results with this realistic intensification already show the importance of capturing atmosphere-ocean teleconnections in climate simulations for reliable future simulations of the ecosystems. We simulated large differences in future ecosystem responses under our "intensified" ENSO scenario, as large as the differences we calculated for the present day with and without ENSO simulations. In other words, if we were to predict vegetation response to future climate change by using GCM outputs as they are, it would be as when simulating the present-day vegetation with climate data without any ENSO contribution.

Apart from the temporal and strength mismatch, the GCM simulations also produce different spatial patterns for tropical Pacific SST-eastern African rainfall teleconnection. Therefore, in our modification we chose to correct for this spatial pattern by using the relationships we obtained from the observed datasets as this correction did not influence the temporal behaviour and the peakiness of the ENSO signal retrieved from the GCM simulations. As a result, our findings can be compared for present-day patterns directly.

Another finding in our study regarding the spatial patterns was that, while the region that explains the most variability in eastern African rainfall is closer to the Niño-3.4 region in our historical analysis, it shifts towards the Niño-4 region in the EOT analysis with GCM outputs. In our methodology the coupling of tropical Pacific sea surface temperature-eastern African rainfall variability emerges from the data, and this shift in the influence region agrees well with previous studies that identify an increase in the intensity of central Pacific (CP) ENSO in the future from GCM outputs (Kim and Yu, 2012). While CP ENSO is thought to be forced by changes in the atmospheric circulation, the mechanism for eastern Pacific ENSO is rather associated with thermocline variations in the oceanic circulation (Yu et al., 2010), and the seasonal impacts produced by these two types of ENSO could differ. For example, wetter patterns of EP El Niño events in eastern Africa might not occur under CP El Niño events, and CP La Niña events could induce drier conditions in the southern parts of the region than EP La Niña events (Wiedermann et al., 2017), which could result in prolongated drought events for the eastern African region. Future work with further discrimination of CP-EP event types could help better anticipate the ecosystem responses to such seasonal extremes.

\section{Conclusions}

In this study, we translated the lack of ability of GCMs to account for ENSO teleconnections into quantified discrepancies in terms of ecosystem responses. We investigated the relationship between interannual eastern African rainfall variability and ENSO events using empirical orthogonal teleconnection (EOT) analysis, and found a robust connection from observational datasets, in agreement with previous studies, while confirming that GCM outputs are still not reliable for capturing this pertinent rainfall variability due to ENSO. While the strength of this relationship is not homogeneous among the region, and the patterns of vegetation response presented opposite characteristics in the northern and southern areas, ENSO influence on eastern African vegetation and in return its carbon and hydrological fluxes was apparent. The simulated vegetation responses showed non-negligible differences under climate with and without stronger ENSO signal in relation to mitigation efforts for future climate change. We conclude that the future vegetation would be different from what is simulated under these climate model outputs lacking accurate ENSO contribution to the extent of ignoring the ENSO influence altogether. Comparably with findings from previous studies linking vegetation-climate interactions, we discussed the importance of accounting for this influence which can bring further environmental stress to eastern Africa. Overall, our results highlight that more robust projections on coupled atmosphere-ocean teleconnections can help reduce large uncertainties of the future magnitude and sign of carbon sink provided by terrestrial ecosystems by improving our understanding of the vegetation response.

Code availability. All the $\mathrm{R}$ code used in this study can be found at github.com/istfer/ENSOpaper. 
Appendix A: Supplementary figures
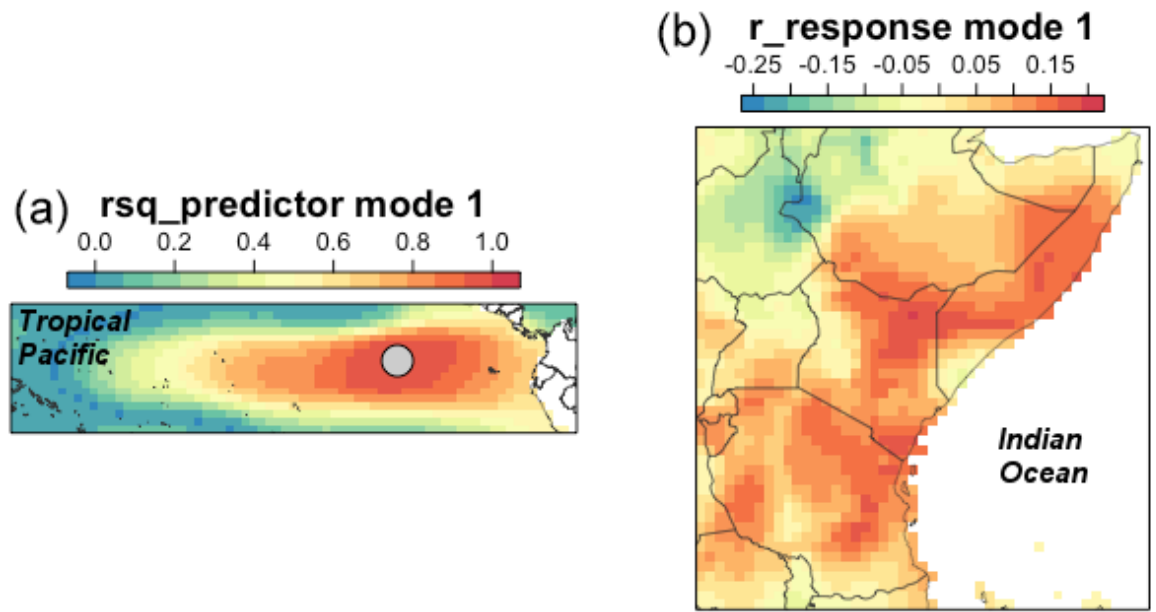

\section{(c) Time series eot 1 explained response domain variance: $0.85 \%$}

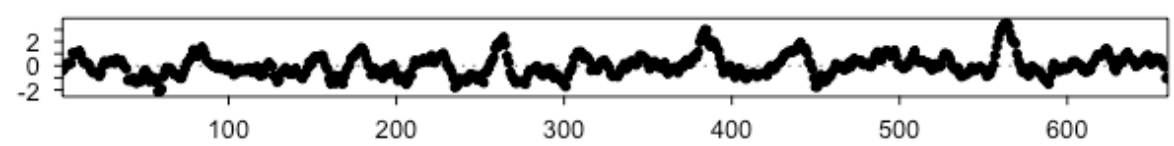

Figure A1. Coupled ocean-atmosphere teleconnection between Pacific sea surface temperatures and eastern African rainfall retrieved from historical observations. (a) The coefficients of determination for the predictor field highlight that the Niño-3.4 region explains the variance in the response domain the most. (b) Correlation coefficients of each pixel of the eastern African (response) domain show that spatially the coastal parts and the north-western area are explained by the predictor field. (c) Time series of tropical Pacific SST anomalies at the base point (the grey circle in a) of the first mode as an ENSO signal. 

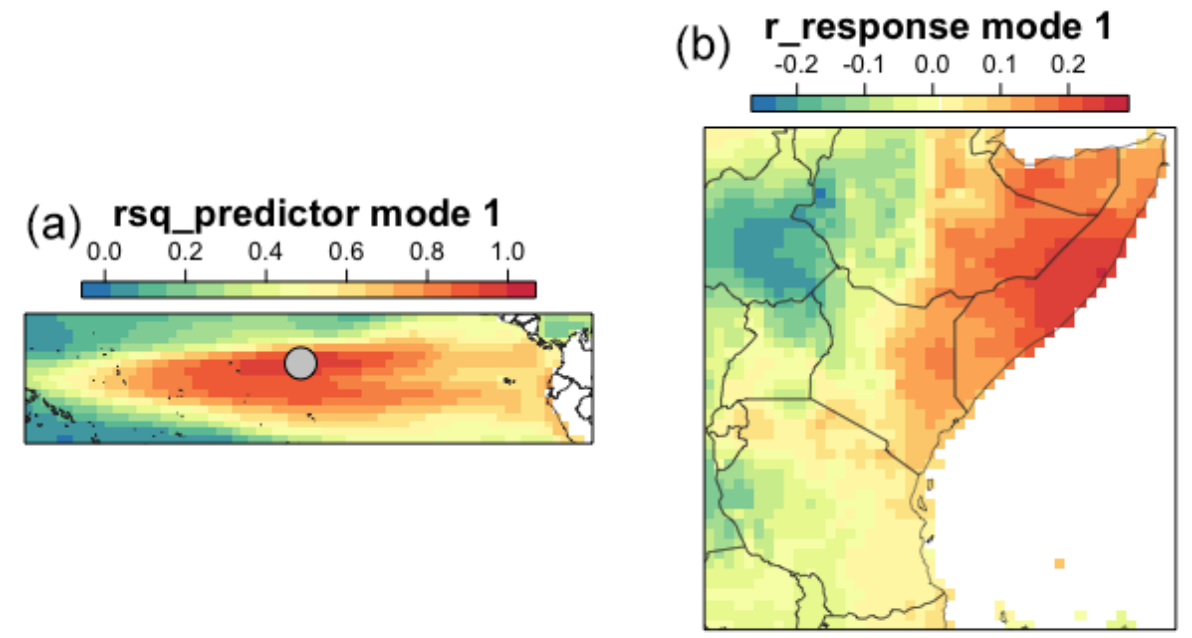

\section{(c) Time series eot 1 explained response domain variance: $1.08 \%$}

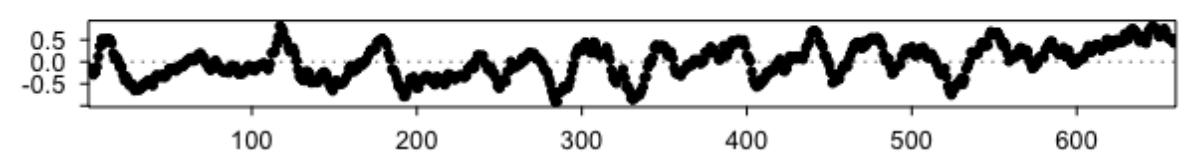

Figure A2. EOT analysis for the historical period from the GCM simulations. Panels as explained in Fig. A1: (a) the coefficients of determination for the predictor field. (b) Correlation coefficients of each pixel of the eastern African (response) domain. (c) Time series at the base point of the mode.

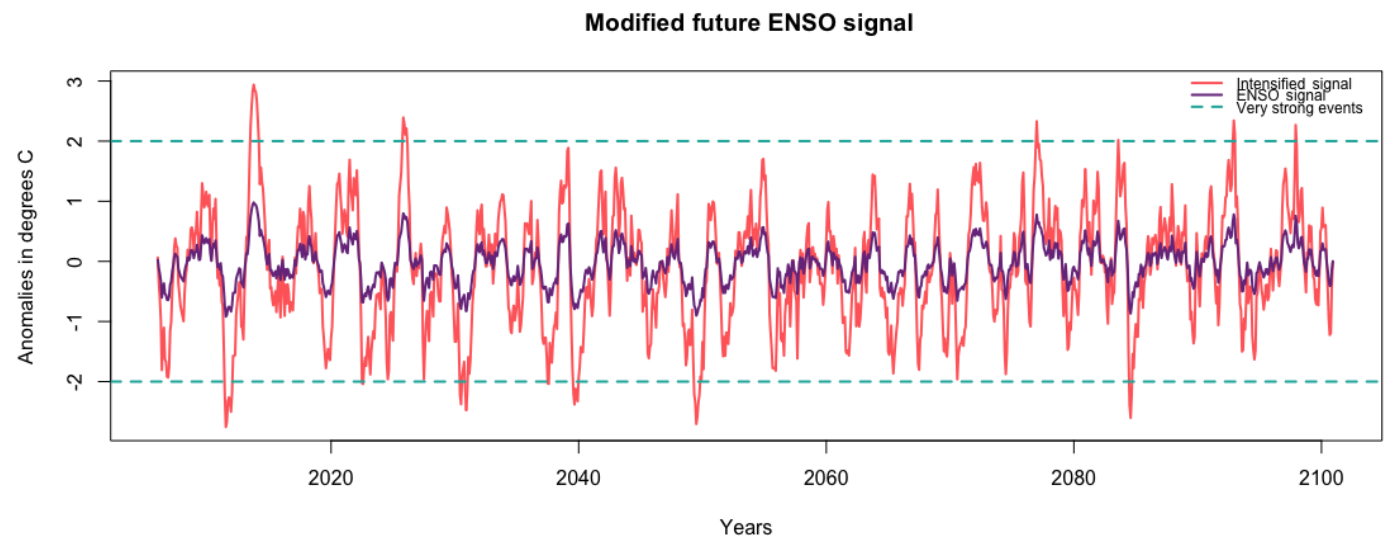

Figure A3. Intensified ENSO signal. Purple line: future ENSO signal retrieved from GCM outputs for the 2006-2100 period. Red line: intensified signal such that anomalies peak as strongly as recorded amplitudes $\left( \pm 2.0^{\circ} \mathrm{C}\right)$. The dashed line marks the very strong ENSO event threshold. 


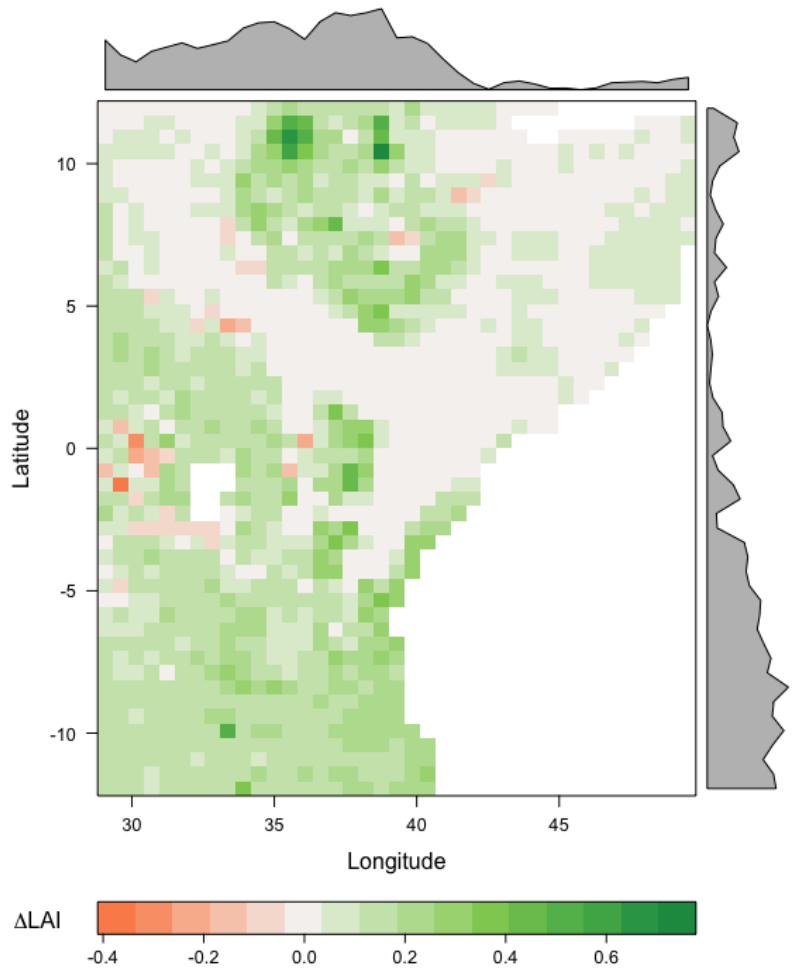

Figure A4. Simulated woody vegetation leaf area index (LAI) differences under future climate scenario RCP8.5 (without any manipulation to the ENSO signal) and present day $(\mathrm{PD})(\triangle \mathrm{LAI}=\mathrm{RCP} 8.5-\mathrm{PD})$.

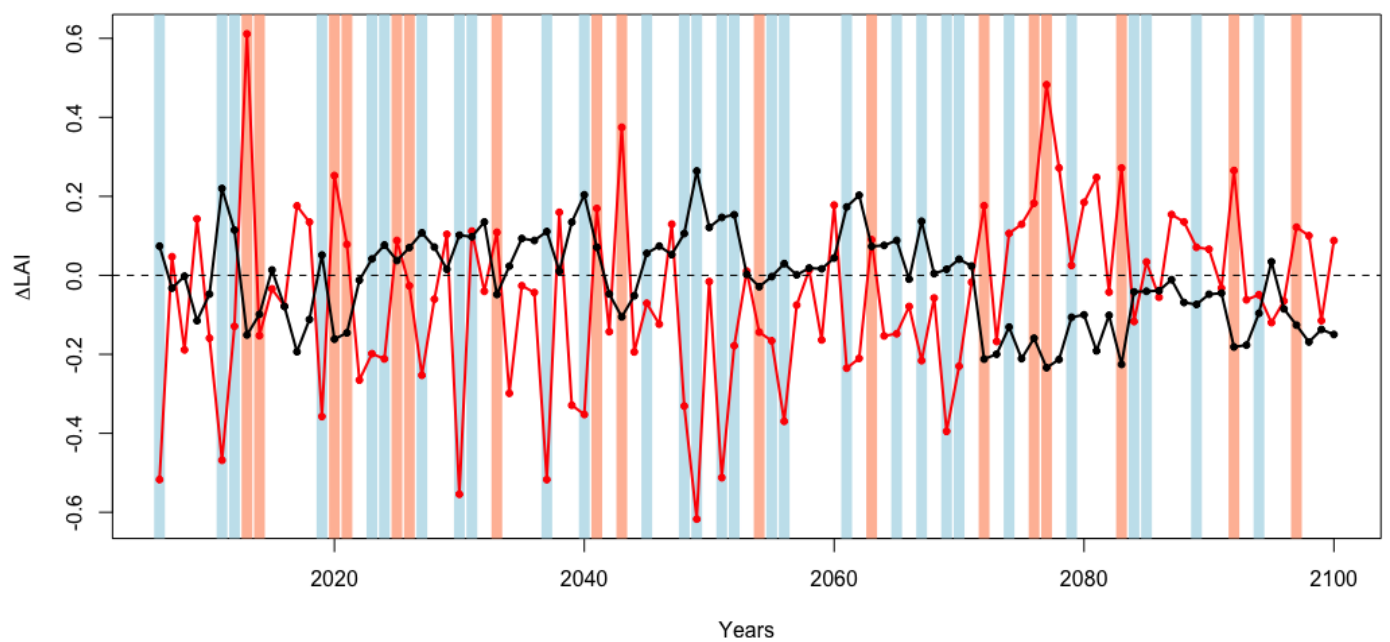

Figure A5. Temporal differences in LAI according to future simulations with and without intensified ENSO contribution $(\Delta=$ with intensification - without intensification). Black line: northern transect; red line: southern transect. Vertical blue lines: all moderate $\left(<-1.0^{\circ} \mathrm{C}\right)$ La Niña years identified for the future period (2006-2100); vertical pink lines: moderate $\left(>1.0^{\circ} \mathrm{C}\right)$ El Niño years. 


\section{Appendix B: Full GCM names}

- CCCma-CanESM2: Canadian Centre for Climate Modelling and Analysis - The second generation Canadian Earth System Model (Flato et al., 2000).

- CERFACS CNRM-CM5: Centre Européen de Recherche et de Formation Avanciée, Centre National de Recherches Météorologiques, Climate Model 5 (Voldoire et al., 2013).

- IPSL CM5A-MR: Institut Pierre Simon Laplace Climate Model 5A Medium Resolution (Hourdin et al., 2013).

- QCCCE CSIRO Mk3-6-0: Queensland Climate Change Centre of Excellence, Commonwealth Scientific and Industrial Research Organization, Mark 3.6 (Collier et al., 2013).
- ICHEC EC-EARTH: Irish Centre for High End Computing, EC-Earth (Sterl et al., 2012).

- MIROC5: Atmosphere and Ocean Research Institute (The University of Tokyo), National Institute for Environmental Studies, and Japan Agency for Marine-Earth Science and Technology, Model for Interdisciplinary Research on Climate (Watanabe et al., 2010).

- MPI-M ESM-LR: Max Planck Institute for Meteorology, Earth System Model, Low Resolution (Giorgetta et al., 2013).

- NCC NorESM1-M: Norwegian Climate Centre, Norwegian Earth System Model (Bentsen et al., 2013).

- NOAA GFDL-ESM2M: National Oceanic and Atmospheric Administration, Geophysical Fluid Dynamics Laboratory (Dunne et al., 2012). 
Competing interests. The authors declare that they have no conflict of interest.

Acknowledgements. I. Fer was funded by the DAAD, grants to F. Jeltsch, and the German Research Foundation (DFG) Graduate School GRK1364 programme (Shaping Earth's Surface in a Variable Environment - Interactions between tectonics, climate and biosphere in the African-Asian monsoonal region). F. Jeltsch and $B$. Tietjen acknowledge the support by the BMBF in the framework of the OPTIMASS project (01LL1302A and 01LL1302B). We thank the Plant Ecology and Nature Conservation Group of Potsdam University for the inspiring discussions, and Appelhans for helpful discussions on the EOT method. We are grateful to the Biogeosciences editor and the two anonymous reviewers for their comments and suggestions that helped us improve this paper to a great extent.

Edited by: Akihiko Ito

Reviewed by: two anonymous referees

\section{References}

Abdi, A. M., Vrieling, A., Yengoh, G. T., Anyamba, A., Seaquist, J. W., Ummenhofer, C. C., and Ardö, J.: The El Niño - La Niña cycle and recent trends in supply and demand of net primary productivity in African drylands, Climatic Change, 138, 111-125, https://doi.org/10.1007/s10584-016-1730-1, 2016.

Ahlström, A., Schurgers, G., Arneth, A., and Smith, B.: Robustness and uncertainty in terrestrial ecosystem carbon response to CMIP5 climate change projections, Environ. Res. Lett., 7, 044008, https://doi.org/10.1088/1748-9326/7/4/044008, 2012.

Ahlström, A., Raupach, M. R., Schurgers, G., Smith, B., Arneth, A., Jung, M., Reichstein, M., Canadell, J. G., Friedlingstein, P., Jain, A. K., Kato, E., Poulter, B., Sitch, S., Stocker, B. D., Viovy, N., Wang, Y. P., Wiltshire, A., Zaehle, S., and Zeng, N.: The dominant role of semi-arid ecosystems in the trend and variability of the land $\mathrm{CO}_{2}$ sink, Science, 348, 895-899, https://doi.org/10.1126/science.aaa1668, 2015.

Anyah, R. O. and Semazzi, F. H. M.: Variability of East African rainfall based on multiyear RegCM3 simulations, Int. J. Climatol., 27, 357-371, https://doi.org/10.1002/joc.1401, 2007.

Appelhans, T. and Nauss, T.: Spatial patterns of sea surface temperature influences on East African precipitation as revealed by empirical orthogonal teleconnections, Front. Earth Sci., 4, 3, https://doi.org/10.3389/feart.2016.00003, 2016.

Appelhans, T., Detsch, F., and Nauss, T.: Remote: empirical orthogonal teleconnections in R, J. Stat. Softw., 65, 1-19, https://doi.org/10.18637/jss.v065.i10, 2015.

Bentsen, M., Bethke, I., Debernard, J. B., Iversen, T., Kirkevåg, A., Seland, Ø., Drange, H., Roelandt, C., Seierstad, I. A., Hoose, C., and Kristjánsson, J. E.: The Norwegian Earth System Model, NorESM1-M - Part 1: Description and basic evaluation of the physical climate, Geosci. Model Dev., 6, 687-720, https://doi.org/10.5194/gmd-6-687-2013, 2013.

Black, E., Slingo, J., and Sperber, K. R.: An observational study of the relationship between excessively strong short rains in Coastal East Africa and Indian Ocean SST,
Mon. Weather Rev., 131, 74-94, https://doi.org/10.1175/15200493(2003)131<0074:AOSOTR>2.0.CO;2, 2003.

Bobe, R.: The evolution of arid systems in eastern Africa, J. Arid Environ., 66, 564-584, https://doi.org/10.1016/j.jaridenv.2006.01.010, 2006.

Brandt, M., Rasmussen, K., Peñuelas, J. P., Tian, F., Schurgers, G., Verger, A., Mertz, O., Palmer, J. R. B., and Fensholt, R.: Human population growth offsets climate-driven increase in woody vegetation in sub-Saharan Africa, Nat. Ecol. Evol., 1, 0081, https://doi.org/10.1038/s41559-017-0081, 2017.

Cai, W., Borlace, S., Lengaigne, M., van Rensch, P., Collins, M., Vecchi, G., Timmermann, A., Santoso, A., McPhaden, M. J., Wu, L., England, M. H., Wang, G., Guilyardi, E., and Jin, F.-F.: Increasing frequency of extreme El Niño events due to greenhouse warming, Nat. Clim. Change, 5, 111-116, https://doi.org/10.1038/nclimate2100, 2014.

Cai, W., Wang, G., Santoso, A., McPhaden, M. J., Wu, L., Jin, F.F., Timmermann, A., Collins, M., Vecchi, G., Lengaigne, M., England, M. H., Dommenget, D., Takahashi, K., and Guilyardi, E.: Increased frequency of extreme La Niña events under greenhouse warming, Nat. Clim. Change, 5, 132-137, https://doi.org/10.1038/nclimate2492, 2015.

Collier, M. A., Rotstayn, L. D., Kim, K.-Y., Hirst, A. C., and Jeffrey, S. J.: Ocean circulation response to anthropogenic-aerosol and greenhourse gas forcing in the CSIRO-Mk3.6 coupled climate model, Aust. Meteorol. Oceanogr. J., 63, 27-39, 2013.

Detsch, F., Otte, I., Appelhans, T., Hemp, A., and Nauss, T.: Seasonal and long-term vegetation dynamics from $1 \mathrm{~km}$ GIMMSbased NDVI time series at Mt. Kilimanjaro, Remote Sens. Environ., 178, 70-83, https://doi.org/10.1016/j.rse.2016.03.007, 2016.

Dietrich, J. P., Schmitz, C., Lotze-Campen, H., Popp, A., and Müller, C.: Forecasting technological change in agriculture - an endogenous implementation on global land use model, Technol. Forecast. Soc., 81, 236-249, https://doi.org/10.1016/j.techfore.2013.02.003, 2014.

Doherty, R. M., Sitch, S., Smith, B., Lewis, S. L., and Thornton, P. K.: Implications of future climate and atmospheric $\mathrm{CO}_{2}$ content for regional biogeochemistry, biogeography and ecosystem services across East Africa, Global Change Biol., 16, 617640, https://doi.org/10.1111/j.1365-2486.2009.01997.x, 2010.

Dunne, J. P., John, J. G., Adcroft, A. J., and Griffies, S. M., Hallberg, R. W., Shevliakova, E., Stouffer, R. J., Cooke, W., Dunne, K. A., Harrison, M. J., Krasting, J. P., Malyshev, S. L., Milly, P. C. D., Phillipps, P. J., Sentman, L. T., Samuels, B. L., Spelman, M. J., Winton, M., Wittenberg, A. T., and Zadeh, N.: GFDL's ESM2 Global Coupled Climate-Carbon Earth System Models, J. Climate, 25, 6646-6665, https://doi.org/10.1175/JCLI-D-1100560.1, 2012.

Endris, H. S., Omondi, P., Jain, S., Lennard, C., Hewitson, B., Chang'a, L., Awange, J. L., Dosio, A., Ketiem, P., Nikulin, G., Panitz, H.-J., Büchner, M., Stordal, F., and Tazalika, L.: Assessment of the performance of CORDEX regional climate models in simulating eastern Africa rainfall, J. Climate, 26, 8453-8475, https://doi.org/10.1175/JCLI-D-12-00708.1, 2013.

FAOSTAT: available at: http://faostat.fao.org (last access: 10 March 2017), 2016.

Fer, I., Tietjen, B., and Jeltsch, F.: High-resolution modelling closes the gap between data and model simulations for Mid-Holocene 
and present-day biomes of East Africa, Palaeogeogr. Palaeocl., 444, 144-151, https://doi.org/10.1016/j.palaeo.2015.12.001, 2016.

Flato, G. M., Boer, G. J., Lee, W. G., McFarlane, N. A., Ramsden, D., Reader, M. C., and Weaver, A. J.: The Canadian Centre for Climate Modeling and Analysis global coupled model and its climate, Clim. Dynam., 16, 451-467, https://doi.org/10.1007/s003820050339, 2000.

Forzieri, G., Alkama, R., Miralles, D. G., and Cescatti, A.: Satellites reveal contrasting responses of regional climate to the widespread greening of Earth, Science, 356, 1180-1184, https://doi.org/10.1126/science.aal1727, 2017.

Gerten, D., Schaphoff, S., Haberlandt, U., Lucht, W., and Sitch, S.: Terrestrial vegetation and water balance - hydrological evaluation of a dynamic global vegetation model, J. Hydrol., 286, 249270, https://doi.org/10.1016/j.jhydrol.2003.09.029, 2004.

Giorgetta, M. A., Jungclaus, J. Reick, C. H., Legutke, S., Bader, J., Böttinger, M., Brovkin, V., Crueger, T., Esch, M., Fieg, K., Glushak, K., Gayler, V. Haak, H. Hollweg, H.-D., Ilyina, T., Kinne, S., Kornblueh, L., Matei, D., Mauritsen, T., Mikolajewicz, U., Mueller, W., Notz, D., Pithan, F., Raddatz, T., Rast, S., Redler, R., Roeckner, E., Schmidt, H., Schnur, R., Segschneider, J., Six, K. D., Stockhause, M., Timmreck, C., Wegner, J., Widmann, H., Wieners, K.-H., Claussen, M., Marotzke, J., and Stevens, B.: Climate change from 1850 to 2100 in MPI-ESM simulations for the coupled model intercomparison project phase 5, J. Adv. Model. Earth Syst., 5, 572-597, https://doi.org/10.1002/jame.20038, 2013.

Goddard, L. and Graham, N. E.: Importance of the Indian Ocean for simulating rainfall anomalies over eastern and southern Africa, J. Geophys. Res., 104, 19099-19116, https://doi.org/10.1029/1999JD900326, 1999.

Harris, I., Jones, P. D.,, Osborn, J. T., and Lister, D. H.: Updated high-resolution grids of monthly climatic observations - the CRU TS3.10 dataset, Int. J. Climatol., 34, 623-642, https://doi.org/10.1002/joc.3711, 2014.

Hickler, T., Smith, S., Sykes, M. T., Davis, M. B., Sugita, S., and Walker, K.: Using a generalized vegetation dynamics in Northeastern USA, Ecology, 86, 519-530, https://doi.org/10.1890/020344, 2004.

Kelly-Hope, L. and Thomson, M. C.: Climate and Infectious Diseases, in: Seasonal Forecasts, Climatic Change and Human Health: Health and Climate, edited by: Thomson, M. C., GarciaHerrera, R., and Beniston, M., Springer Netherlands, Dordrecht, 31-70, 2008.

Hourdin, F., Foujols, M. A., Codron, F., Guemas, V., Dufresne, J.L., Bony, S., Denvil, S., Guez, L., Lott, F., Ghattas, J., Braconnot, P., Marti, O., Meurdesoif, Y., and Bopp, L.: Impact of the LMDZ atmospheric grid configuration on the climate and sensitivity of the IPSL-CM5A coupled model, Clim. Dynam., 40, 2167-2192, https://doi.org/10.1007/s00382-012-1411-3, 2013.

Huang, B., Banzon, V. F., Freeman, E., Lawrimore, J., Liu, W., Peterson, T. C., Smith, T. M., Thorne, P. W., Woodruff, S. D., and Zhang, H.-M.: Extended Reconstructed Sea Surface Temperature version 4 (ERSS T.v4): Part I. Upgrades and intercomparisons, J. Climate, 28, 911-930, https://doi.org/10.1175/JCLI-D14-00006.1, 2014.

Indeje, M., Semazzi, F. H. M., and Ogallo, L. J.: ENSO signals in East African Rainfall Seasons, Int. J. Cli- matol., 20, 19-46, https://doi.org/10.1002/(SICI)10970088(200001)20:1<19::AID-JOC449>3.0.CO;2-0, 2000.

Ivory, S. J., Russell, J., and Cohen, A. S.: In the hot seat: insolation, ENSO, and vegetation in the African tropics, J. Geophys. Res.Biogeo., 118, 1347-1358, https://doi.org/10.1002/jgrg.20115, 2013.

Kim, S. T. and Yu, J.-Y.: The two types of ENSO in CMIP5 models, Geophys. Res. Lett., 39, L11704, https://doi.org/10.1029/2012GL052006, 2012.

Kovats, R. S., Bouma, M. J., Worrall, S. H. E., and Haines, A.: El Niño and health, Lancet, 362, 1481-1489, https://doi.org/10.1016/S0140-6736(03)14695-8, 2003.

Lim, E.-P., Hendon, H. H., Zhao, M., and Yin, Y.: Inter-decadal variations in the linkages between ENSO, the IOD and southeastern Australia springtime rainfall in the past 30 years, Clim. Dynam., 49, 97-112, https://doi.org/10.1007/s00382-016-33288, 2017.

Liu, W., Huang, B., Thorne, P. W., Banzon, V. F., Zhang, H.M., Freeman, E., Lawrimore, J., Peterson, T. C., Smith, T. M., and Woodruff, S. D.: Extended Reconstructed Sea Surface Temperature version 4 (ERSS T.v4): Part II. Parametric and structural uncertainty estimations, J. Climate, 28, 931-951, https://doi.org/10.1175/JCLI-D-14-00007.1, 2014.

Meegan, J. and Bailey, C. L.: Rift Valley fever, in: The arboviruses: Epidemiology and ecology, edited by: Monath, T. P., CRC Press Inc., Boca Raton, 1989.

Miralles, D. G., van den Berg, M. J., Gash, J. H., Parinussa, R. M., de Jeu, R. A. M., Beck, H. E., Holmes, T. R. H., Jiménez, C., Verhoest, N. E. C., Dorigo, W. A., Teuling, A. J., and Dolman, A. J.: El Niño - La Niña cycle and recent trends in continental evaporation, Nat. Clim. Change, 4, 122-126, https://doi.org/10.1038/nclimate2068, 2014.

Moncrieff, G. R., Scheiter, S., Bond, W. J., and Higgins, S. I.: Increasing atmospheric $\mathrm{CO}_{2}$ overrides the historical legacy of multiple stable biome states in Africa, New Phytol., 201, 908-915, https://doi.org/10.1111/nph.12551, 2014.

Moss, R. H., Edmonds, J. A., Hibbard, K. A., Manning, M. R., Rose, S. K., van Vuuren, D. P., Carter, T. R., Emori, S., Kainuma, M., Kram, T., Meehl, G. A., Mitchell, J. F. B., Nakicenovic, N., Riahi, K., Smith, S. J., Stouffer, R. J., Thomson, A. M., Weyant, J. P., and Wilbanks, T. J.: The next generation of scenarios for climate change research and assessment, Nature, 463, 747-756, https://doi.org/10.1038/nature08823, 2010.

Nazarenko, L., Schmidt, G., Miller, R. L., Tausnev, N., Kelley, M., Ruedy, R., Russell, G. L., Aleinov, I., Bauer, M., Bauer, S., Bleck, R., Canuto, M., Cheng, Y., Clune, T. L., Genio, A. D. D., Faluvegi, G., Hansen, J. E., Healy, R. J., Kiang, N. Y., Koch, D., Lacis, A. A., LeGrande, A. N., Lerner, J., Lo, K. K., Menon, S., Oinas, V., Perlwitz, J. P., Puma, M. J., Rind, D., Romanou, A., Shindell, D. T., Sun, S., Tsigaridis, K., Unger, N., Voulgarakis, A., Yao, M.-S., and Zhang, J.: Future climate change under RCP emission scenarios with GISS ModelE2, J. Adv. Model. Earth Syst., 7, 244-267, https://doi.org/10.1002/2014MS000403, 2015.

Nicholson, S. E.: The nature of rainfall variability over Africa on time scales of decades to millenia, Global Planet. Change, 26, 137-158, https://doi.org/10.1016/S0921-8181(00)00040-0, 2000 . 
Nicholson, S. E.: A detailed look at the recent drought situation in the Greater Horn of Africa, J. Arid Environ., 103, 71-79, https://doi.org/10.1016/j.jaridenv.2013.12.003, 2014.

Nicholson, S. E.: Long-term variability of the East African shortrains and its links to large-scale factors, Int. J. Climatol., 35, 3979-3990, https://doi.org/10.1002/joc.4259, 2015.

Nikulin, G., Jones, C., Giorgi, F., Asrar, G., Büchner, M., Cerezo-Mota, R., Christensen, O. B., Déqué, M., Fernandez, J., Hänsler, A., van Meijgaard, E., Samuelsson, P., Sylla, M. B., and Sushama, L.: Precipitation climatology in an ensemble of CORDEX-Africa regional climate simulations, Am. Meteorol. Soc., 25, 6058-6078, https://doi.org/10.1175/JCLI-D-11$00375.1,2012$.

Poulter, B., Frank, D., Ciais, P., Myneni, R. B., Andela, N., Bi, J., Broquet, G., Canadell, J. G., Chevallier, F., Liu, Y. Y., Running, S. W., Sitch, S., and van der Werf, G. R.: Contribution of semi-arid ecosystems to interannual variability of global carbon cycle, Nature, 509, 600-603, https://doi.org/10.1038/nature13376, 2014.

R: A Language and Environment for Statistical Computing, v2.5-8, R Foundation for Statistical Computing, Vienna, Austria, available at: http://www.R-project.org/ (last access: 18 July 2016), 2015.

Riahi, K., Rao, S., Krey, V., Cho, C., Chirkov, V., Fischer, G., Kindermann, G., Nakicenovic, N., and Rafaj, P.: RCP8.5 - a scenario of comparatively high greenhouse gas emissions, Climatic Change, 109, 33-57, https://doi.org/10.1007/s10584-011-0149y, 2011.

Ropelewski, C. F. and Halpert, M. S.: Quantifying Southern Oscillation-rainfall relationships, J. Climate, 9, 1043-1059, https://doi.org/10.1175/15200442(1996)009<1043:QSOPR>2.0.CO;2, 1996.

Sanford, T., Frumhoff, P. C., Luers, A., and Gulledge, J.: The climate policy narrative for a dangeroously warming world, Nat. Clim. Change, 4, 164-166, https://doi.org/10.1038/nclimate2148, 2014.

Scheiter, S. and Savadogo, S.: Ecosystem management can mitigate vegetation shifts induced by climate change in West Africa, Ecol. Model., 332, 19-27, https://doi.org/10.1016/j.ecolmodel.2016.03.022, 2016.

Scheiter, S., Langan, L., and Higgins, S. I.: Nextgeneration dynamic global vegetation models: learning from community ecology, New Phytol., 198, 957-969, https://doi.org/10.1111/nph.12210, 2013.

Schreck, C. J. and Semazzi, F. H. M.: Variability of the recent climate of East Africa, Int. J. Climatol., 24, 681-701, https://doi.org/10.1002/joc.1019, 2004.

Shisanya, C. A., Recha, C., and Anyamba, A.: Rainfall variability and its impact on normalized difference vegetation index in arid and semi-arid lands of Kenya, Int. J. Geosci., 2, 36-47, https://doi.org/10.4236/ijg.2011.21004, 2011.

Sitch, S., Smith, B., Prentice, I. C., Arneth, A., Bondeau, A., Cramer, W., Kaplan, J. O., Levis, S., Lucht, W., Sykes, M. T., Thonicke, K., and Venevsky, S.: Evaluation of ecosystem dynamics, plant geography and terrestrial carbon cycling in the LPJ dynamic global vegetation model, Global Change Biol., 9, 161185, https://doi.org/10.1046/j.1365-2486.2003.00569.x, 2003.

Smith, B., Prentice, I. C., and Sykes, M. T.: Representation of vegetation dynamics in the modelling of terrestrial ecosys- tems: comparing two contrasting approaches within European climate space, Global Ecol. Biogeogr., 10, 621-637, https://doi.org/10.1046/j.1466-822X.2001.t01-1-00256.x, 2001.

Sterl, A., Bintanja, R., Brodeau, L., Gleeson, E., Koenigk, T., Schmith, T., Semmler, T., Severijns, C., Wyser, K., and Yang, S.: A look at the ocean in the EC-Earth climate model, Clim. Dynam., 39, 2631-2657, https://doi.org/10.1007/s00382-011-1239$2,2012$.

Thonicke, K., Venevsky, S., Sitch, S., and Cramer, W.: The role of fire disturbance for global vegetation dynamics: coupling fire into a dynamic vegetation model, Global Ecol. Biogeogr., 10, 661-667, https://doi.org/10.1046/j.1466822X.2001.00175.x, 2001.

Thornton, P. K., Ericksen, P. J., Herrero, M., and Challinor, A. J.: Climate variability and vulnerability to climate change: a review, Global Change Biol., 20, 3313-3328, https://doi.org/10.1111/gcb.12581, 2014.

Trenberth, K. E.: Forecasts of the development of the 1997-98 El Niño event, CLIVAR Exchanges, 3, 4-14, 1998.

van den Dool, H. M., Saha, S., and Johansson, A.: Empirical orthogonal teleconnections, J. Climate, 13, 1421-1435, https://doi.org/10.1175/1520 0442(2000)013<1421:EOT>2.0.CO;2, 2000.

Vecchi, G. A. and Wittenberg, A. T.: El Niño and our future climate: where do we stand?, Wires Clim. Change, 1, 260-270, https://doi.org/10.1002/wcc.33, 2010.

Voldoire, A., Sanchez-Gomez, E., Salas y Mélia, D., Decharme, B., Cassou, C., Sénési, S., Valcke, S., Beau, I., Alias, A., Chevallier, M., Déqué, M., Deshayes, J., Douville, H., Fernandez, E., Madec, G., Maisonnave, E., Moine, M.-P., Planton, S., Saint-Martin, D., Szopa, S., Tyteca, S., Alkama, R., Belamari, S., Braun, A., Coquart, L., and Chauvin, F.: The CNRMCM5.1 global climate model: description and basic evaluation, Clim. Dynam., 40, 2091-2121, https://doi.org/10.1007/s00382011-1259-y, 2013.

Waha, K., Müller, C., Bondeau, A., Dietrich, J. P., Kurukulasuriya, P., Heinke, J., and Lotze-Campen, H.: Adaptation to climate change through he choice of cropping system and sowing date in sub-Saharan Africa, Global Environ. Change, 23, 130 143, https://doi.org/10.1016/j.gloenvcha.2012.11.001, 2013.

Watanabe, M., Suzuki, T., O'ishi, R., Komuro, Y., Watanabe, S., Emori, S., Takemura, T., Chikira, M., Ogura, T., Sekiguchi, M., Takata, K., Yamazaki, D., Yokohata, T., Nozawa, T., Hasumi, H., Tatebe, H., and Kimoto, M.: Improved Climate Simulation by MIROC5: Mean States, Variability, and Climate Sensitivity, J. Climate, 23, 6312-6335, https://doi.org/10.1175/2010JCLI3679.1, 2010.

Wiedermann, M., Siegmund, J. F., Donges, F. J., Kurths, J., and Donner, R. V.: Differential imprints of distinct ENSO flavors in global extreme precipitation patterns, Geophys. Res. Lett., in press, 2017.

Wolff, C., Haug, G. H., Timmermann, A., Damsté, J. S. S., Brauer, A., Sigman, D. M., Cane, M. A., and Verschuren, D.: Reduced interannual rainfall variability in East Africa during the Last Ice Age, Science, 333, 743-747, https://doi.org/10.1126/science.1203724, 2011. 
Yu, J.-Y., Kao, H.-Y., and Lee, T.: Subtropics-Related interannual sea surface temperature variability in the Central Equatorial Pacific, J. Climate, 23, 2869-2884, https://doi.org/10.1175/2010JCLI3171.1, 2010.
Zaehle, S., Sitch, S., Smith, B., and Hatterman, F.: Effects of parameter uncertainties on the modeling of terrestrial biosphere dynamics, Global Biogeochem. Cy., 19, GB3020, https://doi.org/10.1029/2004GB002395, 2005. 